\title{
Microstructural Architecture, Microstructures, and Mechanical Properties for a Nickel-Base Superalloy Fabricated by Electron Beam Melting
}

\author{
L.E. MURR, E. MARTINEZ, S.M. GAYTAN, D.A. RAMIREZ, B.I. MACHADO, \\ P.W. SHINDO, J.L. MARTINEZ, F. MEDINA, J. WOOTEN, D. CISCEL, U. ACKELID, \\ and R.B. WICKER
}

Microstructures and a microstructural, columnar architecture as well as mechanical behavior of as-fabricated and processed INCONEL alloy 625 components produced by additive manufacturing using electron beam melting (EBM) of prealloyed precursor powder are examined in this study. As-fabricated and hot-isostatically pressed ("hipped") [at $1393 \mathrm{~K}$ $\left(1120^{\circ} \mathrm{C}\right)$ ] cylinders examined by optical metallography (OM), scanning electron microscopy (SEM), transmission electron microscopy (TEM), energy-dispersive (X-ray) spectrometry (EDS), and X-ray diffraction (XRD) exhibited an initial EBM-developed $\gamma^{\prime \prime}$ (bct) $\mathrm{Ni}_{3} \mathrm{Nb}$ precipitate platelet columnar architecture within columnar [200] textured $\gamma$ (fcc) Ni-Cr grains aligned in the cylinder axis, parallel to the EBM build direction. Upon annealing at $1393 \mathrm{~K}$ $\left(1120^{\circ} \mathrm{C}\right.$ ) (hot-isostatic press (HIP)), these precipitate columns dissolve and the columnar, $\gamma$, grains recrystallized forming generally equiaxed grains (with coherent $\{111\}$ annealing twins), containing $\mathrm{NbCr}_{2}$ laves precipitates. Microindentation hardnesses decreased from $\sim 2.7$ to $\sim 2.2 \mathrm{GPa}$ following hot-isostatic pressing ("hipping"), and the corresponding engineering $(0.2 \mathrm{pct})$ offset yield stress decreased from 0.41 to $0.33 \mathrm{GPa}$, while the UTS increased from 0.75 to $0.77 \mathrm{GPa}$. However, the corresponding elongation increased from 44 to $69 \mathrm{pct}$ for the hipped components.

DOI: $10.1007 / \mathrm{s} 11661-011-0748-2$

(C) The Minerals, Metals \& Materials Society and ASM International 2011

\section{INTRODUCTION}

NiCKEL-BASE superalloys, essentially $\gamma$ (fcc), NiCr solid solution strengthened by additions of $\mathrm{Al}, \mathrm{Ti}, \mathrm{Mo}$, $\mathrm{Ta}$, and $\mathrm{Nb}$ to precipitate a coherent, ordered fcc metastable phase $\gamma^{\prime}\left(\mathrm{Ni}_{3}(\mathrm{Al}, \mathrm{Ti}, \mathrm{Nb})\right)$ or $\gamma^{\prime \prime}$ (bct) phase $\left(\mathrm{Ni}_{3} \mathrm{Nb}\right),{ }^{[1]}$ comprise a broad range of compositions, which have found widespread applications over the past half century. Examples of the more prominent and contemporary applications include jet engine components such as turbine blades, high speed airframe parts, and fossil fuel and nuclear power plant components. These alloys also find a wide variety of corrosion and elevated temperature oxidation envi-

L.E. MURR, Professor and Chairman, E. MARTINEZ, P.W. SHINDO, and J.L. MARTINEZ, Undergraduate Research Assistants, S.M. GAYTAN, D.A. RAMIREZ, and B.I. MACHADO, Graduate Research Assistants, are with the Department of Metallurgical and Materials Engineering, The University of Texas at El Paso, El Paso, TX 79968. Contact e-mail: lemurr@utep.edu F. MEDINA, Manager, and R.B. WICKER, Professor and Director, are with the W.M. Keck Center for 3D Innovation, The University of Texas at El Paso. J. WOOTEN, President, and D. CISCEL, Vice President, are with CalRAM, Inc., Simi Valley, CA 93065. U. ACKELID, Senior Scientist, is with Arcam AB, Mölndal SE-431-37, Sweden.

Manuscript submitted December 20, 2010.

Article published online June 15, 2011 ronment applications, especially CUSTOM-AGE 625*

*CUSTOM-AGE 625 is a registered trademark of Carpenter Technology Corp., Reading, PA.

plus and ALLOY 625**, which are superior to

**ALLOY 625 is a registered trademark of Carpenter Technology Corp., Reading, PA.

INCONEL $718^{\dagger},{ }^{[2]}$ and used in refinery and chemical

${ }^{\dagger}$ INCONEL 718 is a trademark of Special Metals Corporation, New Hartford, NY.

process industries. $^{[3-9]}$

Directional (or unidirectional) solidification processing ${ }^{[10]}$ was extensively applied in the production of aligned eutectic structures, directional columnar structures, and single-crystal Ni-base superalloy turbine blades. These single-crystal turbine blades solidify with a dendritic structure containing microsegregation and second-phase $\left(\gamma^{\prime}\right)$ particles formed by eutectic reactions. In eutectic alloys with reinforced composite properties, a planar 
solid-liquid (phase equilibrium) interface can be established for ingot solidification of eutectic composition carried out under a steep axial thermal gradient achieved by slow withdrawal of the ingot from a furnace such that uniaxial heat flow conditions are established. ${ }^{[1]}$ When this occurs, the two solid eutectic reaction phases (matrix/ eutectic) deposit at the liquid/solid interface and grow parallel to the direction of movement of this reaction front. Consequently, two phases are formed oriented in (or parallel to) the direction of solidification. This often forms eutectic fibers, embedded in the continuous matrix, or parallel lamellae of each phase. Variations in solidification rates of the two phases into the melt create variances in the microstructural features, often forming complex dendrite or related branching patterns.

Jackson and Hunt, ${ }^{[12]}$ in very early investigations, showed that the morphology or architecture observed for unidirectionally solidified eutectic structures will depend upon the relative volume fraction of each phase. Fiber or rod morphology prevails when one phase is present in amounts less than $1 / \pi$ of the total volume. Alternately, when the minor phase constitutes more than $1 / \pi$ of the total volume, a lamellar structure consisting of alternate platelets of the two phases is preferred. Often associated with these parallel microstructures are preferred crystallographic relationships between the interpenetrating crystals of the two phases. This is particularly true for Ni-base eutectic systems such as implicit in $\gamma-\gamma^{\prime}$ structures. ${ }^{[13]}$

The second-phase particles formed in directionally solidified Ni-base superalloys provide composite, coherency/ordered/strengthening of the fcc $\gamma$ matrix. In INCONEL 718 alloys (53Ni-19Cr-3Mo-5Nb-19Fe$0.07 \mathrm{C}$ ) aging reactions produce fine $\gamma^{\prime \prime} \mathrm{Ni}_{3} \mathrm{Nb}$ (bct, $\mathrm{DO}_{22}$ ) coherent disc-shaped precipitates on the $\gamma\{100\}$ planes and ordered fcc $\left(\mathrm{LI}_{2}\right) \gamma^{\prime}$ precipitates with a cubecube $\{100\}$ orientation relationship with the $\gamma$ (Al) matrix. Alloy 625 (INCONEL 625) is similarly strengthened by $\gamma^{\prime}$ and $\gamma^{\prime \prime}\left(\mathrm{Ni}_{3}(\mathrm{Nb}, \mathrm{Ti}, \mathrm{Al})\right)$ during aging, forming fcc cubes and bct discs, respectively, both coincident with the matrix $(\mathrm{NiCr})$ fcc $(\gamma)\{100\}$ planes. In HASTELLOY* B (a Ni-Mo alloy), ordered bet

${ }^{\star}$ HASTELLOY is a registered trademark of Haynes International, Inc., Kokomo, IN.

$\mathrm{Ni}_{4} \mathrm{Mo}$ and fec $\mathrm{Ni}_{3} \mathrm{Mo}$ precipitates form, while in HAYNES $^{\S} 242$ alloy (Ni-Cr-Mo), fine $\mathrm{Ni}_{2}$ (MoCr)

${ }^{\S}$ HAYNES is a registered trademark of Haynes International, Inc., Kokomo, IN.

precipitates can form. ${ }^{[3,4,7,14]}$

Recent development of powder metallurgy, especially for aeronautical applications, demonstrated more homogeneous microstructures suitable for high-temperature components. ${ }^{[9]}$ These processed Ni-base alloys are represented by Udimet products (Seco Tools AB, Fagerston, Sweden). In contrast to conventional directional solidification processing ${ }^{[3,10,11]}$ a relatively new process, electron beam melting (EBM), builds components by the additive layer-by-layer melting of metal or alloy powder layers. ${ }^{[15-17]}$ In this process, illustrated schematically in Figure 1, precursor powder in cassettes is gravity fed onto a build table, where it is sequentially raked into a layer $\sim 50$ - to $100-\mu \mathrm{m}$ thick (depending on the powder size and size distribution), which is preheated by multiple-pass electron beam scanning, and then selectively melted with a melt scan directed by a CAD program. Recent fabrication of Co-base alloy components by EBM from atomized powder produced a novel, discontinuous columnar architecture composed of $\mathrm{Cr}_{23} \mathrm{C}_{6}$ (cubic, fcc) precipitates forming columnar arrays spaced $\sim 2 \mu \mathrm{m} .{ }^{[17]}$ Similar arrays of $\mathrm{Cu}_{2} \mathrm{O}$ precipitates with similar microstructural architecture features were observed in EBM-fabricated $\mathrm{Cu}$ components. ${ }^{[18]}$

This article describes a novel microstructural architecture observed in Ni-base superalloy (alloy 625) components fabricated from atomized powder using EBM. It also represents a comprehensive microstructural and mechanical property characterization study. Optical metallography (OM), scanning electron microscopy (SEM), and transmission electron microscopy (TEM) were used for microstructural characterization, along with energy-dispersive (X-ray) spectrometry (EDS) with the SEM and TEM, and X-ray diffraction (XRD) analysis. Mechanical properties (hardness and tensile, including fracture surface analysis in SEM) were also measured and compared.

\section{EXPERIMENTAL METHODS}

\section{A. EBM Processing}

As illustrated in Figure 1(a) and described briefly previously, EBM processing involves the building of three-dimensional (3-D) components layer by layer from powder. Unlike directional solidification, where melt front propagation creates microstructural architecture, EBM allows for layer-by-layer melt/solidification thermal cycling, which provides complex thermal arrays whose dimensions are determined by electron beam focus and scan spacing. Each melted portion of a raked powder layer is directed by CAD software or model construction, which can also include CT scans of 3 -D products. ${ }^{[3]}$ In this program, cylindrical components measuring $20 \mathrm{~mm}$ in diameter and $80 \mathrm{~mm}$ in length were fabricated from alloy 625 , rotary atomized, rapidly solidified, prealloyed precursor powder illustrated in Figure 1(b) using an Arcam S-12 EBM system (Arcam AB, Molndal, Sweden). Figure 1(c) shows the powder particle sizes and size distribution, having an average size (particle diameter) of $22 \mu \mathrm{m}$. Cylindrical components were convenient for examining transverse (horizontal) and longitudinal (vertical) plane structures and microstructures as well as residual hardness. Cylindrical geometries were also convenient for machining tensile specimens for test and analysis. Comparative rectangular specimens measuring $20 \mathrm{~mm} \times 20 \mathrm{~mm} \times 80 \mathrm{~mm}$ were also cut from rectangular plates measuring $20 \mathrm{~mm} \times 80 \mathrm{~mm} \times 80 \mathrm{~mm}$. 


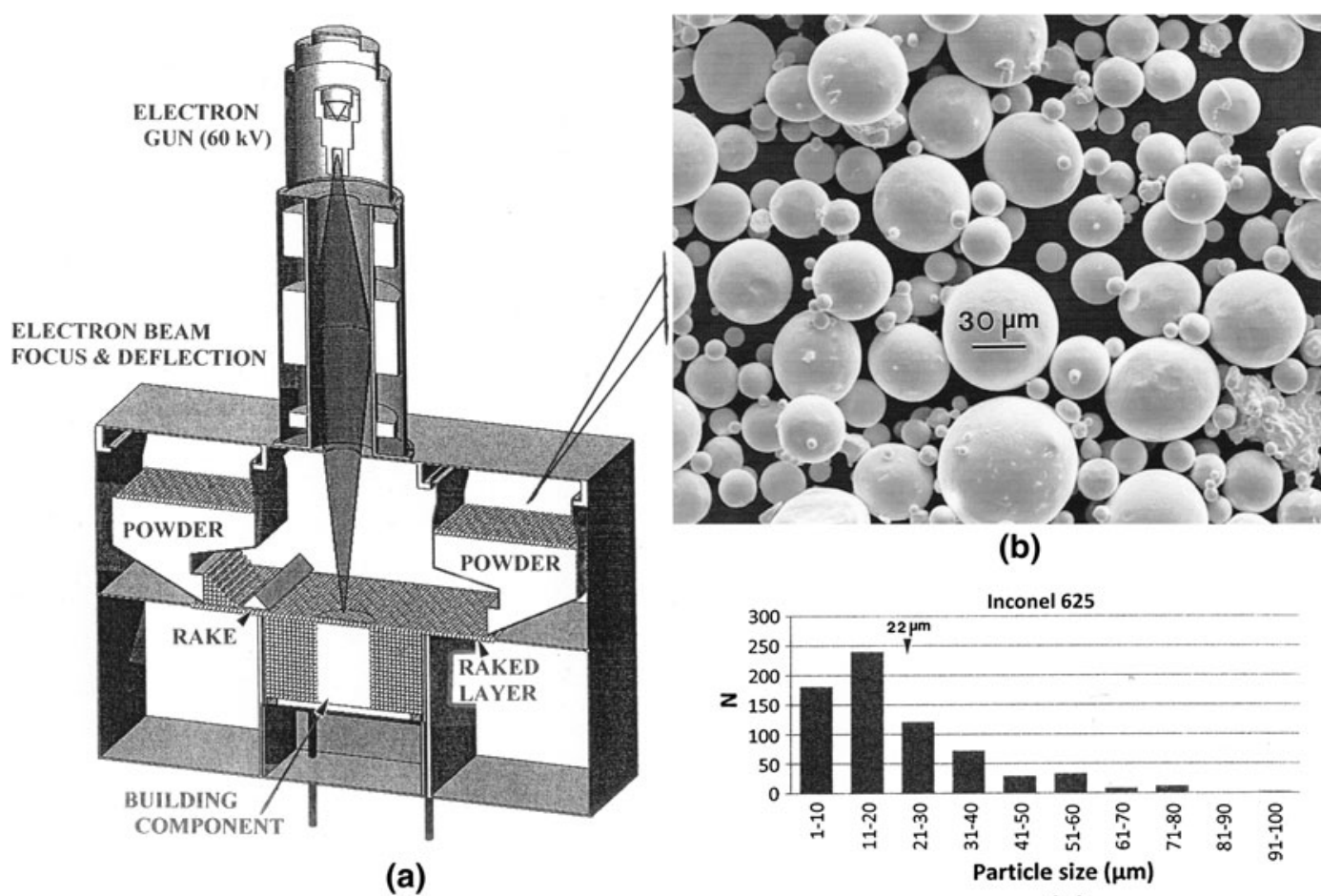

(c)

Fig. 1-(a) EBM system schematic. The precursor powder loaded into cassettes shown is gravity fed and racked onto the build platform in successive layers $\sim 50-\mu \mathrm{m}$ thick. Selected areas of each layer are melted by the scanned beam. (b) SEM view of precursor powder showing spherical particles with varying sizes, as shown in the histogram in $(c)$.

Table I. Chemical Composition for Alloy 625 Precursor Powder and EBM-Fabricated Components

\begin{tabular}{lccccccccccc}
\hline \multicolumn{10}{c}{ Element (wt pct) } \\
\hline Material component & $\mathrm{Ni}$ & $\mathrm{Cr}$ & $\mathrm{Fe}$ & $\mathrm{Mo}$ & $\mathrm{Nb}$ & $\mathrm{C}$ & $\mathrm{Mn}$ & $\mathrm{Si}$ & $\mathrm{Al}$ & $\mathrm{Ti}$ \\
\hline Nominal standard & 61 & 22 & 3.2 & 9.0 & 3.5 & 0.02 & 0.1 & 0.1 & 0.2 & 0.3 \\
Precursor powder mass analysis & 65.7 & 21.3 & 0.4 & 9.3 & 3.7 & 0.004 & - & - & - & 0.002 \\
Precursor powder EDS analysis & 59.1 & 18.8 & - & 7.6 & 3.0 & $*$ & - & - & - & - \\
As-fabricated cylinder EDS analysis & 61.1 & 19.2 & - & 8.8 & 4.7 & $*$ & - & - & - & - \\
\hline
\end{tabular}

*Variances of $\mathrm{C}$ and $\mathrm{O}$ are recorded in the EDS analyses. Oxygen varies from 3.3 pct in the powder to 2.6 pct in the as-fabricated products. $\mathrm{C}$ varies from 8 to $5 \mathrm{pct}$, respectively, and is not considered to be a real compositional feature for the alloy since mass analysis showed essentially no $\mathrm{C}$ or O.

Table I compares the alloy 625 standard (or nominal) chemical analysis compared with the mass analysis for the precursor powder in Figure 1(b) and corresponding EDS analysis of both the precursor powder (Figure 1(b)) and the fabricated cylinders.

\section{B. Structural and Microstructural Analyses: OM, SEM, $T E M$, and $X R D$}

Microstructures for the initial alloy 625 powder and the EBM-fabricated cylindrical samples were initially observed by OM and XRD, followed by SEM and TEM analyses, both employing ancillary EDS attachments for elemental analysis and elemental mapping. TEM analysis also employed selected-area electron diffraction (SAED) analysis and associated dark-field imaging.

OM used a Reichert MEF4 A/M metallograph using digital imaging (Reichert, Inc., Depew, NY). Initial alloy
625 powder (Figure 1(b)) was embedded in an epoxy-base mounting material and ground and polished to expose particle sections, which were electroetched with a solution consisting of $70 \mathrm{~mL}$ phosphoric acid and $30 \mathrm{~mL}$ water, at room temperature, using $5 \mathrm{~V}$ for etching times varying from 5 seconds to 2 minutes. Samples were also etched with 5 pct hydrochloric acid for etching times ranging from 1 to 10 seconds to bring out annealing twin structures or double etches (phosphoric-water + hydrochloric acid). Coupons cut and similarly mounted from the transverse (horizontal) and longitudinal (vertical) planes of fabricated cylinders were also electroetched, as described for the precursor powder. As-fabricated cylinders were also hipped at $1393 \mathrm{~K}\left(1120^{\circ} \mathrm{C}\right)$ at $0.1 \mathrm{GPa}$ pressure for 4 hours in argon, and these processed cylinders were similarly examined by OM.

XRD spectra were analyzed for the precursor powder (Figure 1(b)) and coupons extracted from the horizontal 
and vertical planes for the as-fabricated cylindrical specimens and the hipped specimens. The XRD system was a Brucker AXS-D8 Discover system using a $\mathrm{Cu}$ target (Brucker AXS, Madison, WI).

SEM analysis employed a Hitachi S-4800 field emission SEM (Hitachi America, Pleasonton, CA) fitted with an EDAX EDS system and operated at $20 \mathrm{kV}$ in both the secondary electron and backscatter electron (BSE) imaging modes. The TEM analysis of coupons extracted from the experimental alloy 625 samples, as outlined previously for OM, used sections ground and polished to thicknesses of $\sim 200 \mu \mathrm{m}$. Three-millimeter standard TEM discs were punched, mechanically dimpled, and electropolished in a Tenupol-5 dual jet system (Product of Struers, Inc., Cleveland, $\mathrm{OH}$ ) at temperatures ranging from $247 \mathrm{~K}$ to $245 \mathrm{~K}\left(-26{ }^{\circ} \mathrm{C}\right.$ to $\left.-28{ }^{\circ} \mathrm{C}\right)$, using an electropolishing solution consisting of $200 \mathrm{~mL}$ perchloric acid, $800 \mathrm{~mL}$ methanol at $13 \mathrm{~V}$. TEM analysis was performed in a Hitachi H-9500 high-resolution transmission electron microscope operated at $300 \mathrm{kV}$ and fitted with a goniometer-tilt stage, a digital imaging camera, and an EDAX-EDS elemental (X-ray) mapping analysis attachment (EDAX r-TEM ${ }^{\S \S}$ detector). This

${ }^{\S \S}$ EDAX r-TEM is a trademark of EDAX, Inc., Mahwah, NJ.

system can map areas as small as $20 \mathrm{~nm}$ on a side.

\section{Mechanical Testing}

Micro- and macroindentation hardness measurements were made on specimen sections extracted from as-fabricated and hipped cylinders in the transverse (horizontal) and longitudinal (vertical) planes. Microindentation hardness was also measured for the mounted, polished, and etched precursor powder. The microindentation (Vickers) hardness (HV) was measured using a Vickers diamond indenter in a Shimadzu HMV $=2000$ tester (Shimadzu Scientific Instruments Inc., Columbus, MD) (using 25 and 100 gf or 0.25 and $1 \mathrm{~N}$ load, respectively, for $\sim 10$-second load time). Macrohardness measurements were made using a Rockwell tester with a 1.5 $\mathrm{N}$ load and a C-scale indenter (HRC).

Tensile specimens were machined from the as-fabricated and hipped EBM cylinders and tested in an upgraded TINIUS-OLSEN Universal Testing machine PA.

TINIUS-OLSEN is a trademark of Tinius-Olsen, Inc., Hansham,

(SIN 175118) at a strain rate of $\sim 10^{-3} \mathrm{~s}^{-1}$ at room temperature $\left[295 \mathrm{~K}\left(22^{\circ} \mathrm{C}\right)\right]$. Specimens as-fabricated and hipped were also tested at $811 \mathrm{~K}\left(538{ }^{\circ} \mathrm{C}\right)$. Fracture surface examinations were also performed for failed tensile specimens in the SEM. Tensile specimens were machined from the as-fabricated cylinders hipped at $0.1 \mathrm{GPa}$ for 4 hours at $1393 \mathrm{~K}\left(1120^{\circ} \mathrm{C}\right)$ in argon. This represented $\sim 0.84 T_{M}$, where $T_{M}$, the melting temperature, was $1608 \mathrm{~K}\left(1335^{\circ} \mathrm{C}\right)$.

\section{RESULTS AND DISCUSSION}

\section{A. Structural and Microstructural Characterization of As-Fabricated Cylinders}

Figure 2 shows the characteristic microdendritic structure for the powder particles produced by atomization or rapid solidification rate (RSR) processing. ${ }^{[19,20]}$ The $2-\mu \mathrm{m}$ interdendritic spacing shown in Figure 2 is essentially the same as that exhibited by other RSR-processed Ni-base superalloy powders (e.g., MAR M-200 (60Ni-Zr, Co, Cr, Al, Ti) over the past several decades). ${ }^{[21]}$ Correspondingly, the etched particle section view inserted in Figure 2 confirms that the microdendritic structure exists throughout the particle volume. Vickers microindentation hardness measurements made on sections similar to the optical metallographic image insert in Figure 2 indicated an average value of HV 260 or 2.6 GPa. Figure 3 shows an etched, OM composite view typical of an EBM-fabricated cylinder showing the horizontal plane (normal to the cylinder axis and in the build direction), for comparison with the corresponding powder structure, and the corresponding vertical section views. This structure is characterized by somewhat regular arrays of precipitates spaced $\sim 2 \mu \mathrm{m}$. The microindentation hardness average for these horizontal sections was measured to be HV 280 $(2.8 \mathrm{GPa})$. For the corresponding vertical plane OM views of a fabricated cylinder (parallel to the cylinder

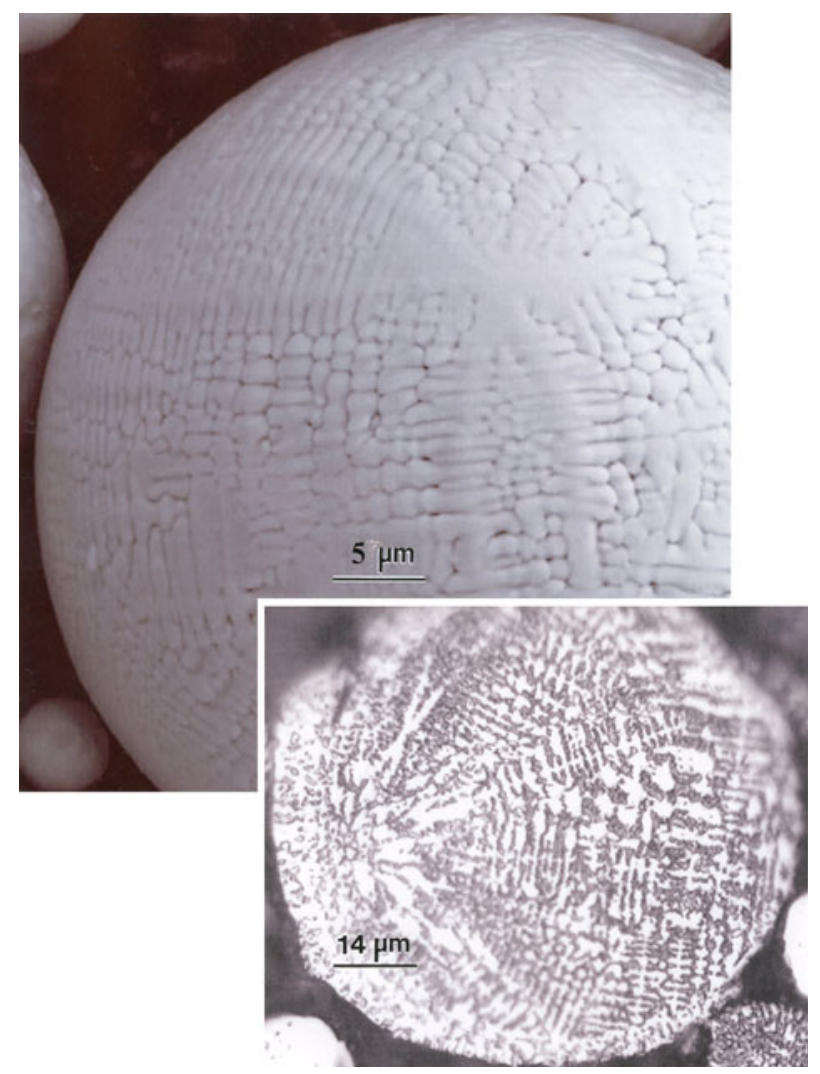

Fig. 2-Magnified SEM view of the INCONEL 625 powder particle showing classical RSR microdendrite structure, with OM view for the corresponding etched cross section inserted, showing the interior microdendritic structure. 


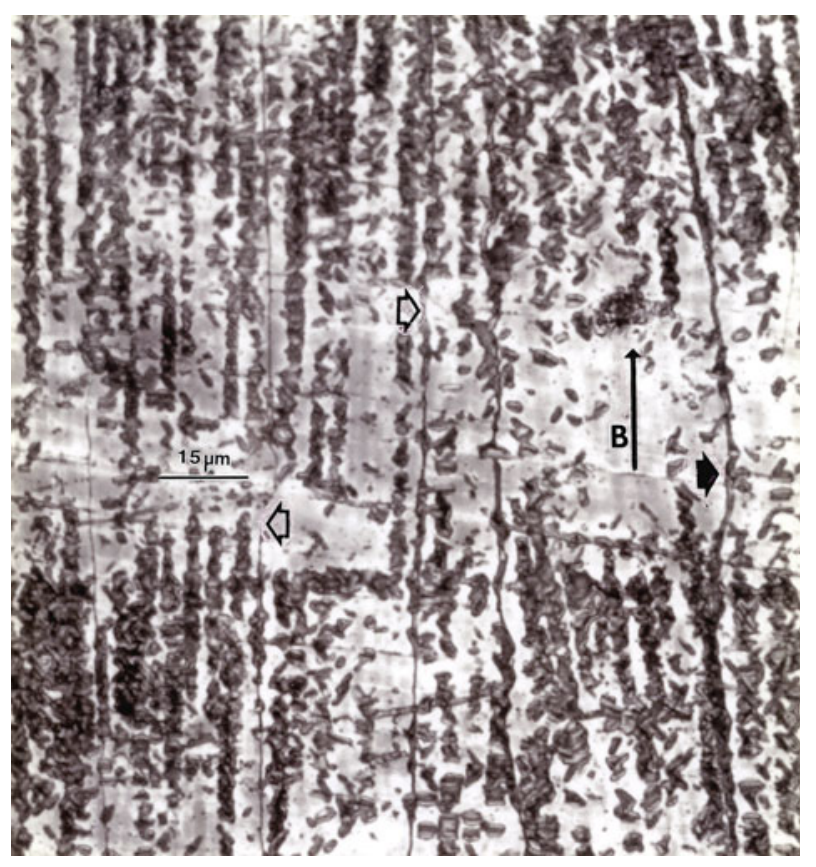

Fig. 3-OM view for a corresponding vertical reference plane parallel to the build direction (B) and the cylinder axis with reference to Fig. 1(a) showing columnar precipitate architecture in the build direction along with columnar grains with GBs indicated by large arrows.

axis and the build direction) shown in Figure 3, the microindentation hardness average was measured to be HV $250(2.5 \mathrm{GPa})$. In contrast to, and in addition to, the horizontal plane arrays in Figure 4, Figure 3 shows irregular or discontinuous columnar-like grain structures composed of precipitate platelets coincident with specific and repetitive fcc Ni-Cr matrix planes. In addition, columnar grains $\sim 20-\mu \mathrm{m}$ wide and in some cases as long as $500 \mu \mathrm{m}$ are observed (arrows in Figure 3). Most precipitate platelets are viewed edgeon in Figure 3, but numerous perspective views for different crystallographic coincidence plane sections, as indicated by arrows in Figure 3, are apparent. For example, the two opposing, unfilled arrows in Figure 3 indicate columnar grain boundaries (GBs), which differ from the one filled arrow at the right. The average spacings of the columnar precipitate structures are dimensionally consistent with the transverse (horizontal plane) views in Figure 4.

The columnar microstructural architectures in Figures 3 and 4 are essentially the same as those characterized by columnar precipitate arrays of $\mathrm{M}_{23} \mathrm{C}_{6}$ carbides in a Co-base superalloy fabricated by EBM, ${ }^{[17]}$ as well as columnar precipitate arrays of $\mathrm{Cu}_{2} \mathrm{O}$ in EBMfabricated $\mathrm{Cu} .{ }^{[22]}$ Similar columns of small $(\sim 10 \mathrm{~nm}) \gamma^{\prime \prime}$ $\left(\mathrm{Ni}_{3} \mathrm{Nb}\right)$ precipitates coincident with $\{100\} \gamma$ have also been observed in the EBM fabrication of an INCONEL 718 alloy by Strondl et al. ${ }^{[23]}$ In the microstructural architectures of precipitate arrays observed in EBMfabricated materials, including Figures 3 and 4, the arrays were characterized by columnar precipitate geometries spaced $\sim 2$ to $3 \mu \mathrm{m}^{[17,22]}$ or larger. ${ }^{[23]}$ These features are created by the EBM-beam scans, which include rapid multipass, orthogonal $(x-y)$, fixed spatial

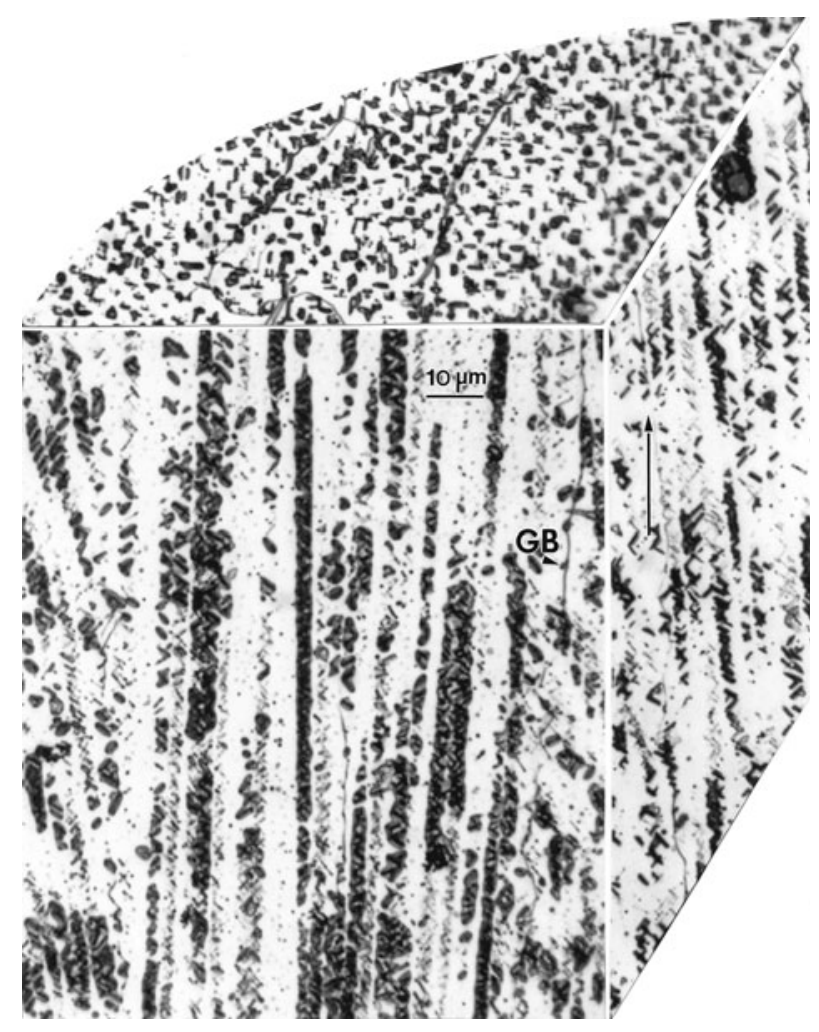

Fig. 4-Magnified OM 3-D reconstruction showing columnar precipitate (microstructural) architecture and columnar GBs containing precipitates. The arrow indicates the EBM process build direction.

rastering of the beam to preheat the layers, as well as the final $x-y$ melt scan. ${ }^{[17,22]}$ The orthogonally rastered zones create thermal partitioning in each layer, conducive to precipitation, which is additively extended forming the columnar architectures. The partial remelting of successive layers also promote a layer-by-layer epitaxy responsible for the partially unidirectional columnar grain growth (Figure 3 ).

As noted earlier, aged alloys 718 and 625 can produce fcc and bet $\mathrm{Ni}_{3} \mathrm{Nb}$ disc and cubic precipitates coincident with the fcc $(\mathrm{Ni}-\mathrm{Cr})$ matrix $\{100\}$ planes including the recent EBM work by Strondl et al. ${ }^{[23]}$ In addition, other Ni-base superalloy compositions commonly also produce fcc $\mathrm{Ni}_{3} \mathrm{Cr}-{ }_{2}$ and bet $\mathrm{Ni}_{4} \mathrm{Mo}$ precipitates. ${ }^{[3,4,7,14,23]}$ $\mathrm{XRD}$ analysis for the precursor powder is reproduced in Figure 5(a). Since the dendritic (microdendritic) structure for the alloy 625 precursor powder does not exhibit any precipitation features (Figure 2), the spectral indices indicated are coincident with solid-solution fcc $\mathrm{NiCr}$ $(a=0.359 \mathrm{~nm}$; space group: $F m-3 m)$. The prominent (111) peak in Figure 5(a), along with the corresponding fcc Ni-Cr peaks, characterizes the dendritic structure and matrix shown in Figure 2. In comparison, the XRD spectrum for the solid, cylindrical component horizontal plane (or section) in Figure 4 is shown for comparison in Figure 5(b). Here (Figure 5(b)), the (111) peak intensity is very low, along with all other peaks (in Figure 5(a)), except for the prominent fcc (200) peak and the (400) fcc peak, absent in Figure 5(a) (XRD for the powder). However, the (400) peak also matches the (226) reflection for $\gamma^{\prime \prime}-\mathrm{Ni}_{3} \mathrm{Nb}$ (bct: $a=0.362 \mathrm{~nm}$, 


\section{PRECURSOR POWDER}

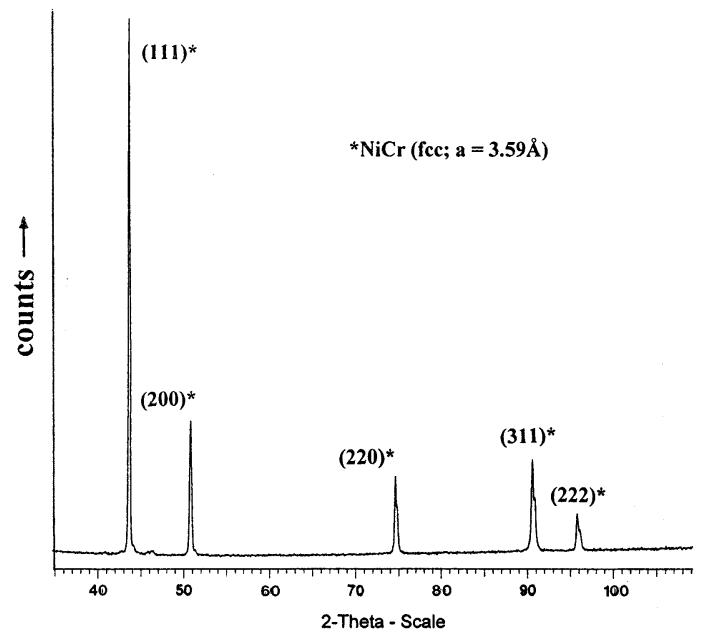

(a)

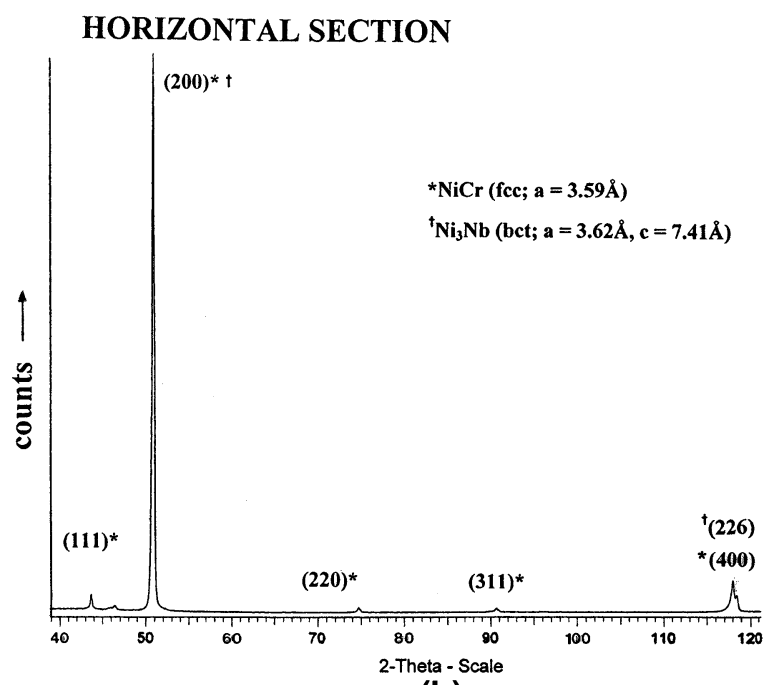

(b)

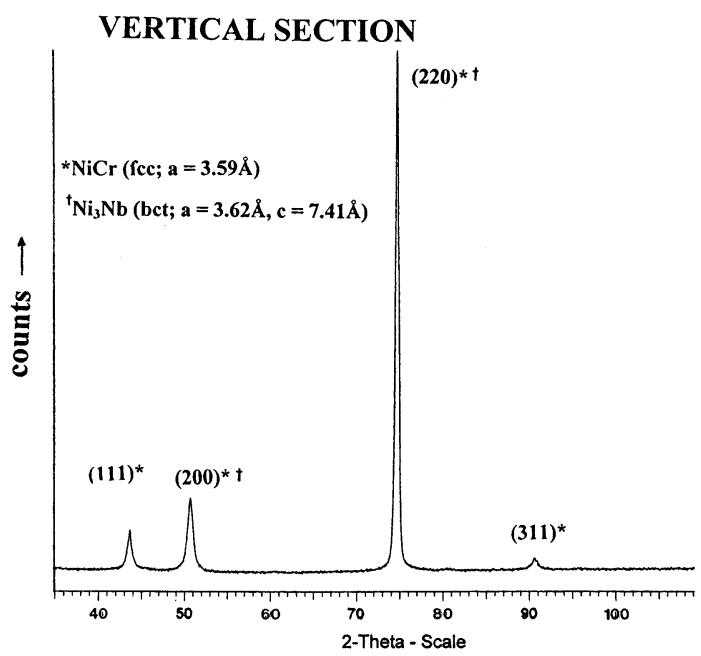

(c)

Fig. 5-XRD spectra for (a) precursor alloy 625 powder, (b) EBM-fabricated cylinder horizontal plane, and (c) vertical plane section.

$c=0.741 \mathrm{~nm}$; space group: $I 4 / \mathrm{mmm})$. Of course, this peak may simply arise due to the prominent (200)[200] horizontal plane texture, although the $\gamma^{\prime \prime}\left(\mathrm{Ni}_{3} \mathrm{Nb}\right)$ bct (200) peak also matches the $\gamma(\mathrm{NiCr}) 200$ peak. The [200] texture in Figure 5(b) represents the growth of the columnar grains shown in Figures 3 and 4 parallel to the build direction and the cylinder axis. The $\gamma^{\prime \prime}$ precipitates in the columns shown in Figures 3 and 4, as noted earlier, are arrayed in apparent coincident fcc crystal planes for the $\gamma \mathrm{Ni}-\mathrm{Cr}$ matrix. The vertical plane (or section) XRD spectrum in Figure 5(c) shows the (220) fcc $\gamma$ peak to be most prominent, with no significant (400) fcc or (226) bct peak. These peak shifts and XRD peak prominences on comparing Figures 5(a) through (c) illustrate corresponding texture variations from the precursor powder particle microdendritic microstructure to the horizontal and vertical build planes, respectively. The vertical plane texture should vary with the geometry or crystallographic coincidence of the vertical sectioning. The weak (226) peak and overlapping (200) peak in Figure 5(b) for the $\gamma^{\prime \prime} \mathrm{Ni}_{3} \mathrm{Nb}$ may arise from the very small platelet volume fraction when viewed down the precipitate columns in the horizontal reference plane. However, in the vertical plane, the platelet volume fraction is reduced to a less detectable level, and the (226) peak disappears. However, since there is a nearly exact $\gamma(200) / \gamma^{\prime \prime}(200)$ peak match as well as $\gamma(220) /$ $\gamma^{\prime \prime}(220)$ and $\gamma(311) / \gamma^{\prime \prime}(311)$, it is not possible to determine the $\gamma^{\prime \prime}$ contribution unambiguously from the XRD data (Figure 5).

While the actual GB features are not particularly prominent in the horizontal reference plane in Figure 4, the corresponding vertical reference planes in Figure 3 show columnar grains and GBs $\sim 15-\mu \mathrm{m}$ wide. Corresponding equiaxed grains in the horizontal plane also average $15 \mu \mathrm{m}$ in size, as shown in Figure 6(a). These boundaries (Figure 6(a)) are observed to have some precipitates in the boundaries, and it is not clear that they are the same as the Ni-Nb columnar, crystallographic precipitate platelets in Figures 3 and 4. In contrast to the horizontal plane structure in Figure 4, Figure 6(a) and areas similar to it occur irregularly 


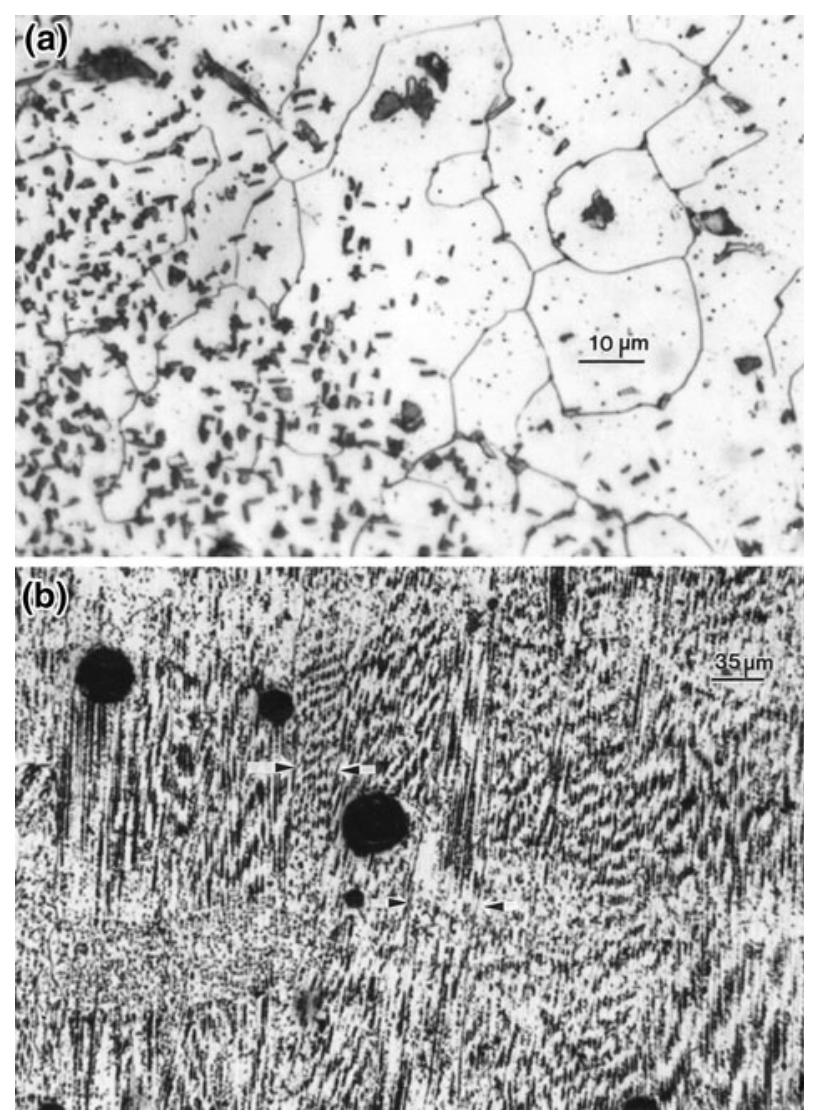

Fig. 6-OM images for horizontal plane section from an EBM-fabricated cylinder showing $(a)$ equiaxed grain structure, and vertical plane section showing columnar precipitates and grains (arrows), and spherical voids $(b)$.

because of EBM scan or localized thermal variations. Very similar observations were shown by Strondl et al. ${ }^{[23]}$ where the precipitates in the boundaries were $\gamma^{\prime}$ in contrast to $\gamma^{\prime \prime}$ precipitates in discontinuous columns similar to Figure 3. The elongated grains in Figure 3 illustrate columnar [200] grains (Figure 5(b)) extending hundreds of microns parallel to the build direction as in the work of Strondl et al. ${ }^{[23]}$ where they also noted a [100] columnar grain texture. Figure 6(b) shows a lower magnification vertical reference plane section, where directional/grain columns are apparent (arrows). Figure 6(b) also shows some evidence of porosity, where the hemispherical voids correspond to the precursor powder diameters (Figure 1(b)). The measured density for the as-fabricated samples was $\sim 8.4 \mathrm{~g} / \mathrm{cm}^{3}$ in contrast to a theoretical density of $8.45 \mathrm{~g} / \mathrm{cm}^{3}$, representing a very low porosity. The density measured after hipping was $\sim 8.5 \mathrm{~g} / \mathrm{cm}^{3}$, indicating some porosity reduction. The columnar grains shown in Figures 3 and 4 are also shown by the arrows in Figure 6(b). It can be concluded that the propensity of horizontal plane grain structures are associated with (200)[200] texture, while the vertical, elongated grains are characteristically a strong (220)[220] texture (comparing the prominent XRD peaks in Figure 5(b) and (c)). This applies at least for the position or geometry of the longitudinal cut

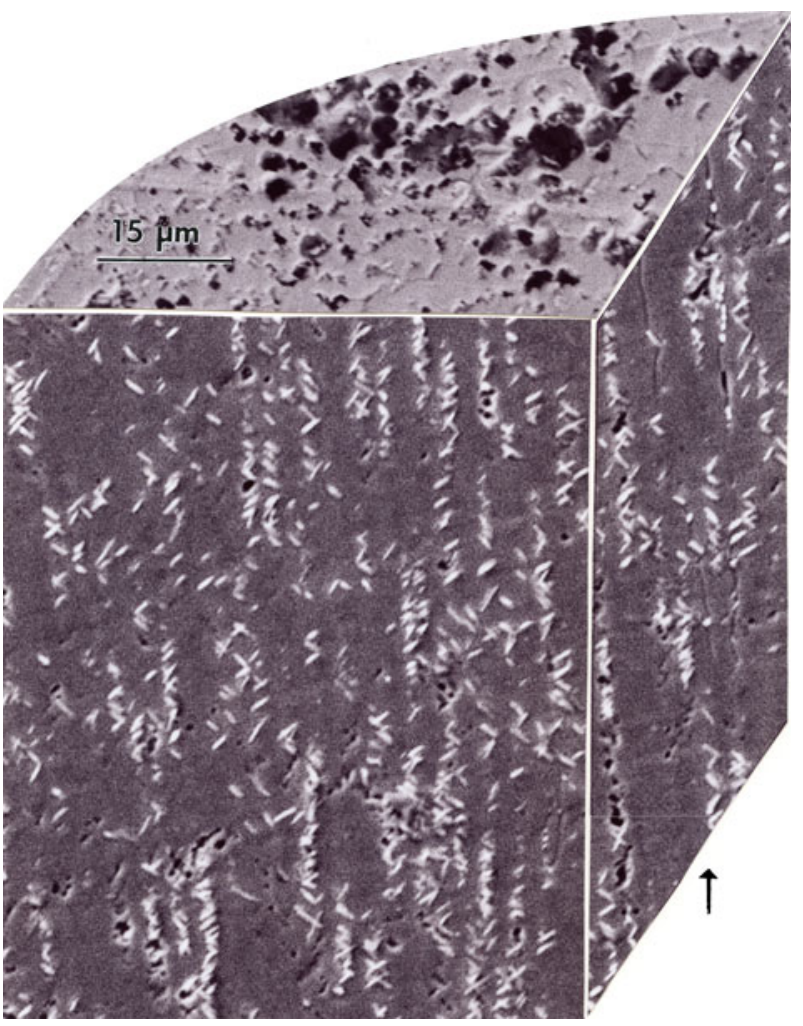

Fig. 7-SEM 3-D composite for precipitate columns in an EBM-fabricated cylindrical component. The horizontal section is a SE image, while the vertical sections are BSE images.

exposing the vertical specimen plane parallel to the build direction, as noted previously.

SEM observations of the precipitate columns provided a clearer view of their nature and geometry (or implicit crystallography), while EDS elemental mapping confirmed their general $\mathrm{Ni}_{x} \mathrm{Nb}$ composition. These features are illustrated in the sequence of observations shown in Figures 7 through 9. Figure 7 shows a mixed secondary electron (SE)-BSE 3-D image composition for precipitate column architectures consistent with Figure 3, while Figure 8 shows higher magnification and more detailed views. Figures 8(a) and (b) confirm the platelet features of the precipitates and their apparent crystallographic geometries. The magnified view in Figure 8(b) shows the precipitate platelet thicknesses to be $<50$ to $100 \mathrm{~nm}$. The etchant to reveal them has created pits and surrounding etched regions, which, as can be observed in Figures 3,4, and 7, exaggerate them. This etching, especially at the precipitate platelet edges, would indicate higher energy regions, and these may occur by coherency strains arising by mismatch between the precipitate platelets and the fcc matrix coincident planes.

EDS mapping for a section of a precipitate column in Figure 8 confirmed the $\mathrm{Nb}$ component. There was no evidence for $\mathrm{Mo}$ or $\mathrm{Cr}$ precipitation or precipitate contribution. Taken together with the XRD spectrum in Figure 5(b) for the horizontal plane for the cylindrical specimen builds, the $\gamma^{\prime \prime} \mathrm{Ni}_{3} \mathrm{Nb}$ platelet characterization becomes more convincing. However, because the 

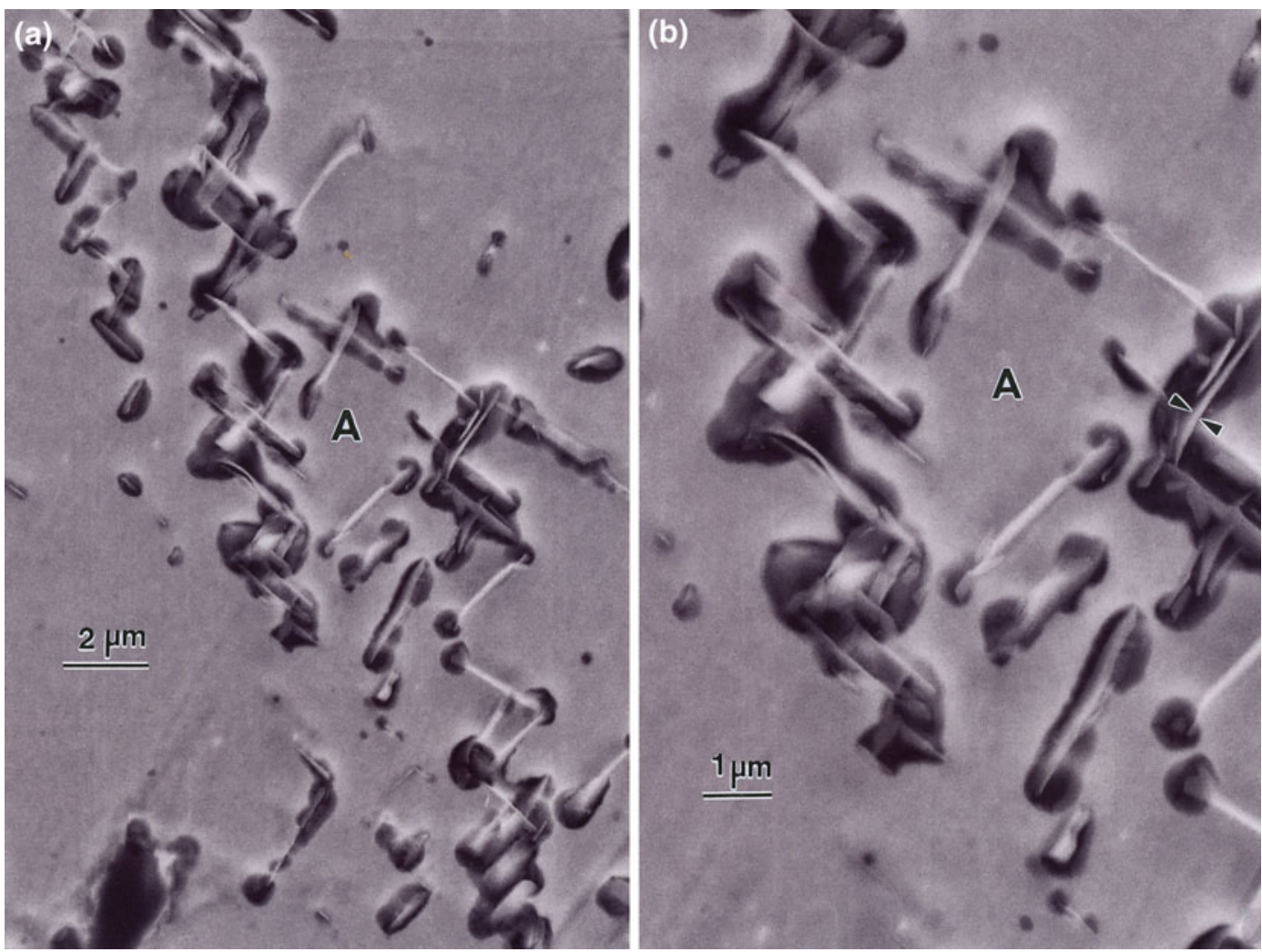

Fig. 8- (a) and (b) Magnified BSE (SEM) images, showing precipitate platelets composing the columnar architecture in Fig. 7. The reference area is denoted $\mathrm{A}$.

precipitates are so thin in contrast to the etched material around them, as shown in Figure 8, the EDS signal (or $\mathrm{X}$-ray count) for $\mathrm{Nb}$ was low.

TEM observations of $\gamma^{\prime \prime}$ precipitate platelets do not exhibit recognizably large strain fields and coincide with crystallographic trace directions consistent with the geometries or implicit crystallography observed in both the horizontal and vertical reference planes by OM and SEM (including SE and BSE imaging), as illustrated in Figures 4,7, and 8. These features are unambiguously shown in Figures 9 and 10. Figure 9(a) shows a horizontal plane-view section exhibiting thin $\gamma^{\prime \prime}$ platelets coincident with the NiCr fcc matrix, while Figures 9(b) and (c) show corresponding vertical plane views (parallel with the build direction noted by the arrow). A TEM column portion (Figure 9(b)) with a corresponding BSE image (Figure 9(c)) shows these thin precipitates perfectly matching the crystallographic trace directions and their intersection geometry, respectively. Both the TEM horizontal and vertical plane section views in Figures 9(a) and (b) were (110) orientations determined by SAED. The trace directions (arrows) noted in Figure 9(a) correspond to $\mathbf{a}-[1 \overline{1} 0], \mathbf{b}-[1 \overline{1} 2]$, and c $-[1 \overline{1} \overline{2}]$, characterizing the fcc matrix (111), (111), and (111) planes, respectively. Figure 9(b) shows the same (110) orientation in the vertical (longitudinal) plane showing the traces for the same (111) and (111) matrix planes, which coincide exactly with the edge views of the precipitate platelets in Figure 9(c) and Figures 4, 7, and 8 . Indeed, these $\{111\}$ planes are normal to the (110) surface plane. The normal, edge-on views of the precipitate platelets in Figure 9(b) indicate them to be lenticular (with the thickness greatest in the plate centers). Measurement of the average edge-on platelet thickness produced values ranging from $<50 \mathrm{~nm}$ in the thinnest plate sections to $\sim 100 \mathrm{~nm}$ in the plate centers, consistent with estimates from the OM images, as noted previously. The irregular shapes of the precipitate platelets observed on inclined (111) planes in Figure 9(a) correspond to the $\mathbf{a}-[1 \overline{1} 0]$ trace direction (a in Figure 9(a)). Figure 10 shows a magnified vertical plane TEM view of thin $\gamma^{\prime \prime}$ precipitate platelets in a (311) orientation. The precipitate platelets are coincident with $\{111\}$ fcc (matrix) planes inclined with the (311) thin section surface, and intersecting along the $[01 \overline{1}]$ and $[\overline{1} 21]$ trace directions, respectively, in Figures 10(a) and (b). Figure 10(a) shows the bright-field TEM precipitate platelet image, while Figure 10(b) shows the corresponding aperture darkfield TEM image using the $\gamma^{\prime \prime}$ (bct) $\mathrm{Ni}_{3} \mathrm{Nb}$ diffraction spot in the SAED pattern insert shown at the arrow. The geometry and crystallography of the $\mathrm{Ni}_{3} \mathrm{Nb}$ platelets in Figures 8 through 10 are consistent with the XRD-[110] ([220]) texture shown in Figure 5(c) for the vertical plane parallel to the build direction. Figures 9(b) and 10 also illustrate considerable densities of dislocations. Figure 10(a) and (b) show dislocation structures within or associated with the $\gamma^{\prime \prime}$ precipitate platelets, which may also result in relieving coherency strains.

The nature of $\mathrm{Ni}-\mathrm{Nb}$ precipitates in nickel-base superalloys was extensively studied more than 4 decades 


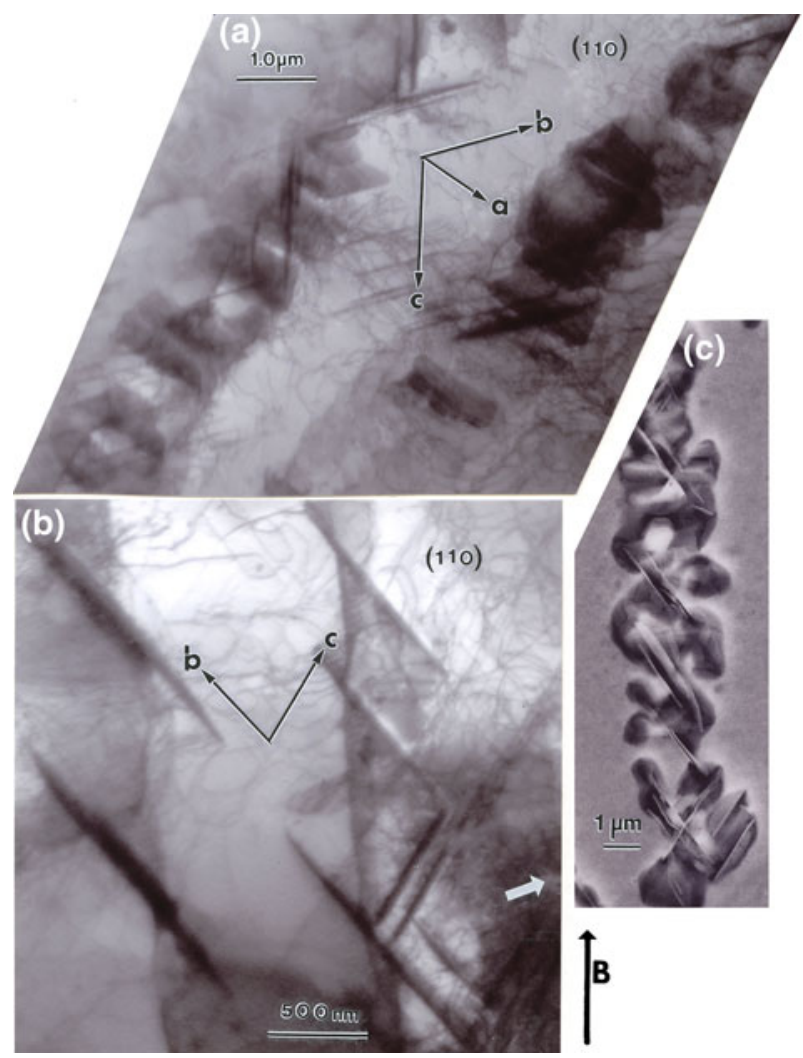

Fig. 9-(a) and (b) TEM bright-field images showing precipitate platelets in (110) plane sections representing the horizontal and vertical sections corresponding to Fig. 7. (c) A comparison with (b) of a BSE image, as in Fig. 8, for the precipitate column (white arrow). The build direction is shown at B. Crystallographic trace directions corresponding to a [110] zone axis are shown by $\mathbf{a}, \mathbf{b}$, and $\mathbf{c}$ in (a) and (b) and are described in the text.

ago. As noted earlier in this article, $\gamma^{\prime \prime} \mathrm{Ni}_{3} \mathrm{Nb}$ discs coherent with the $\gamma(100)$ planes as well as ordered $\gamma^{\prime}$ $\mathrm{Ni}_{3} \mathrm{Nb}$ cube precipitates coherent with $\gamma(100)$ planes were described. ${ }^{[3,4,7,14,23]}$ However, much earlier work by Quinn et al. ${ }^{[24]}$ on $\mathrm{Ni}-\mathrm{Nb}$ alloy subjected to directional solidification showed $\delta-\mathrm{Ni}_{3} \mathrm{Nb}$ Widmanstätten platelets (orthorhombic, $a=0.511 \mathrm{~nm}, b=0.424 \mathrm{~nm}$, $c=0.454 \mathrm{~nm}$; space group: Pmmn) to be defined crystallographically by $(111) / /(010)_{\delta}$ by XRD. A similar relationship was found by Senicourt and Annaruma ${ }^{[25]}$ using electron diffraction. Forbes et al. ${ }^{[2]}$ also described acicular $\delta\left(\mathrm{Ni}_{3} \mathrm{Nb}\right)$-orthorhombic acicular plates coincident with $\{111\}$ planes in overaged INCONEL 718 and $\gamma^{\prime \prime}$ (bct) $\mathrm{Ni}_{3} \mathrm{Nb}$ laths on $\{111\}$ planes during aging of custom age alloy 625. Annaruma and Turpin ${ }^{[26]}$ also reported a semicoherent interface between $\gamma$ and $\delta$ phases and the presence of mismatch dislocations at the interface, where the mismatch along the $\gamma$ growth direction was $\sim 0.5$ pct. In addition, the thermal stability of this alloy after extended heat treatment also provided evidence that the $\gamma / \delta$ interface was low energy.

Since the XRD spectra for the horizontal and vertical reference planes for the EBM-fabricated cylinders (Figure 5(b) and (c)) can be indexed with some wellmatched $\{h k l\}$ or $d$-space values for $\gamma^{\prime}-\mathrm{Ni}_{3} \mathrm{Nb}$ (fcc), $\gamma^{\prime \prime}-\mathrm{Ni}_{3} \mathrm{Nb}$ (bct), $\delta-\mathrm{Ni}_{3} \mathrm{Nb}$ (orthorhombic), as well as

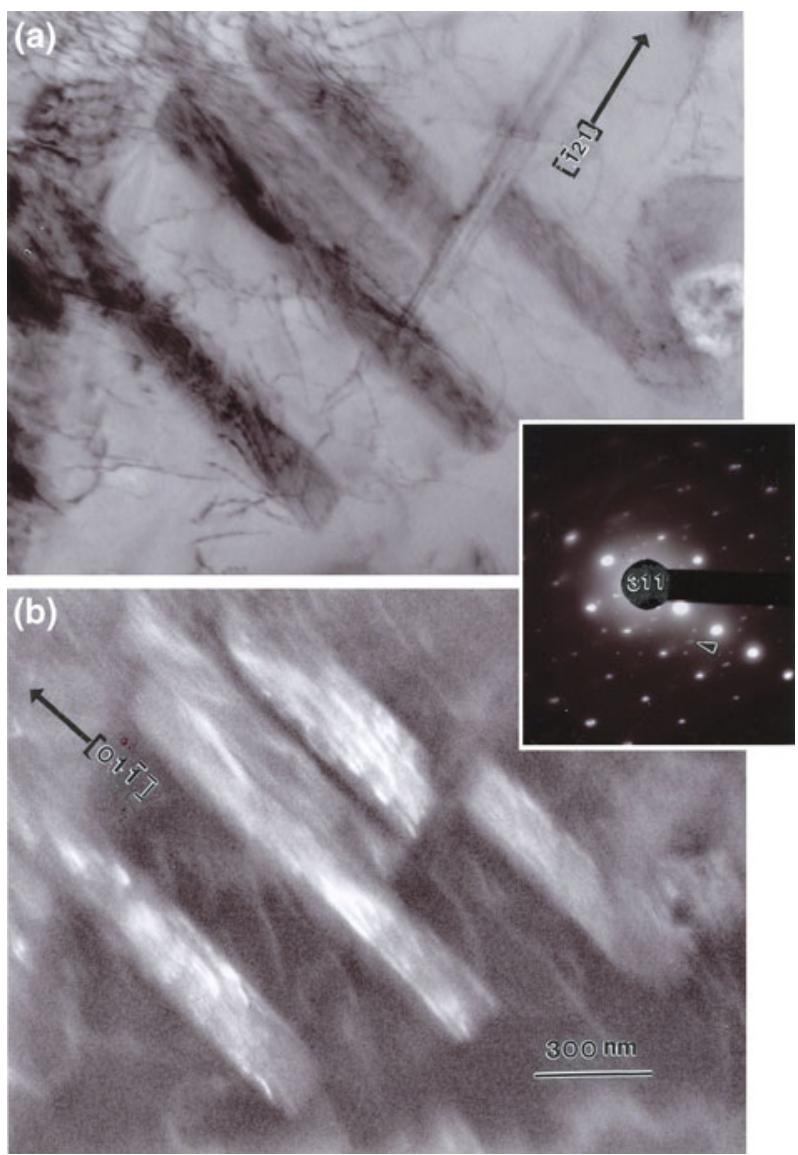

Fig. 10-TEM (a) bright-field and (b) dark-field image sequence showing $\mathrm{Ni}_{3} \mathrm{Nb}$ precipitate platelets coincident with (111) planes in the [011] trace direction in a [311] zone. The aperture dark-field image used the $\mathrm{Ni}_{3} \mathrm{Nb}$-bet reflection shown at the arrow in the SAED pattern insert.

$\mathrm{Ni}_{-0.85} \mathrm{Nb}_{0.15}$ (fcc), the identification of the precipitate platelets rests upon the collective observations (OM, SEM, and TEM) and the SAED evidence, represented typically by Figure 10 . Here, the platelets are unambiguously identified as $\gamma^{\prime \prime}-\mathrm{Ni}_{3} \mathrm{Nb}$ (bct) with the $\mathrm{Ni}-\mathrm{Cr}$ (fcc) matrix $/ \gamma^{\prime \prime}-\mathrm{Ni}_{3} \mathrm{Nb}$ interface crystallography defined by $\|(111) \gamma\|(010) \gamma^{\prime \prime}$. This precipitation phenomenon is a consequence of the unusual thermal conditions in EBM additive-layer fabrication, which can be regarded as a special case of directional solidification. It is interesting to note that the $\{111\} \gamma$ plane coincidence of $\gamma^{\prime \prime}$ is different from the $\{100\} \gamma$ plane coincidence in INCONEL 718 EBM components. ${ }^{[23]}$

Figure 11 amplifies (and confirms) the precipitate identification by providing a high-magnification, brightfield TEM image showing precipitate-plate geometry (Figure 11(a)) in the vertical reference plane. The corresponding SAED pattern, illustrating the plate geometry in the context of the $\{111\}$ plane coincidence, as noted above (and including bct precipitate diffraction spots) (Figure 11(b)), the EDS spectrum showing $\mathrm{Ni}-\mathrm{Nb}-\mathrm{Cr}-\mathrm{Mo}$ peaks (Figure 11(c)), and the corresponding elemental X-ray maps collectively support the precipitate identification. It can be noted in Figure 11(a) 

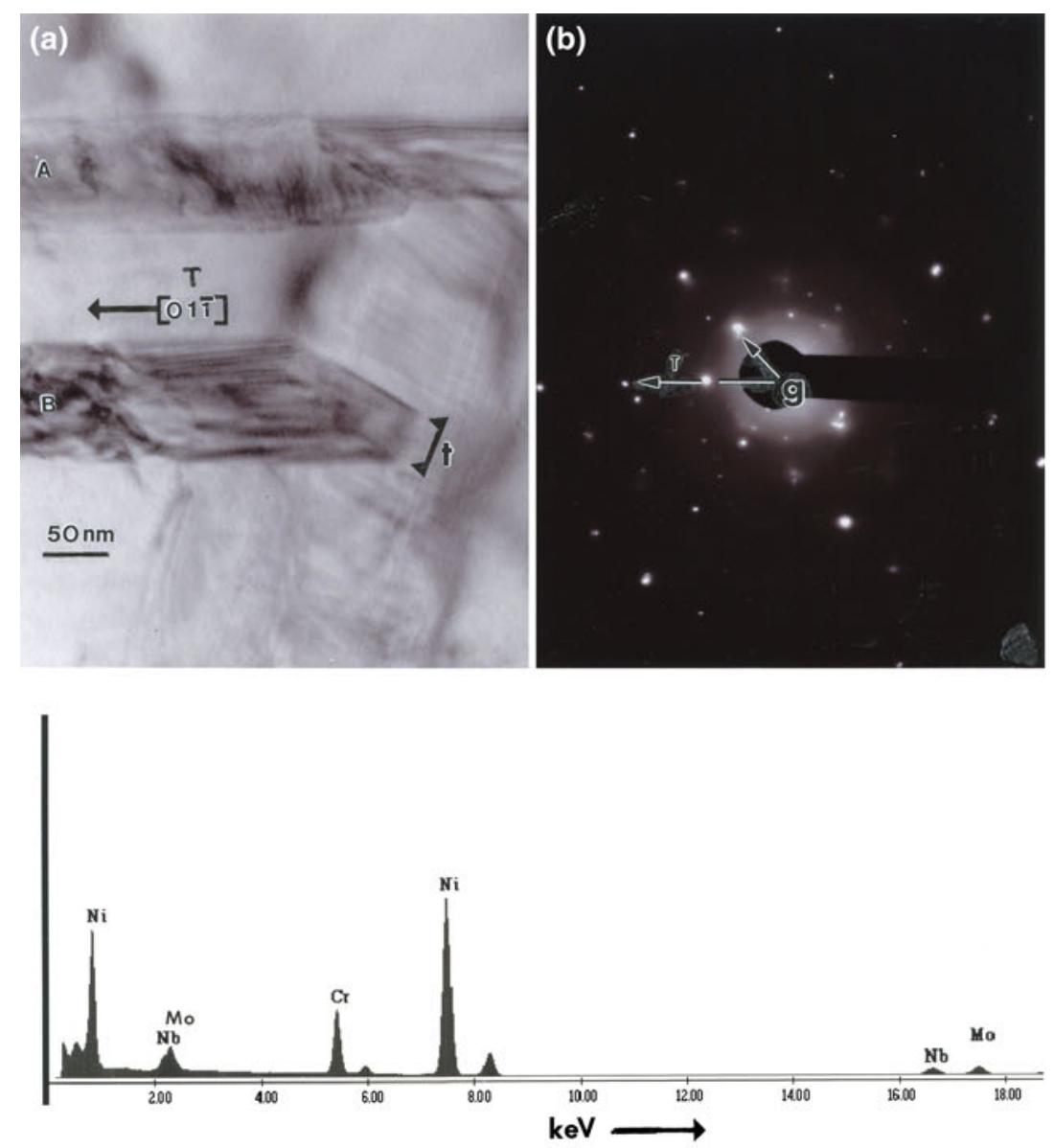

(c)
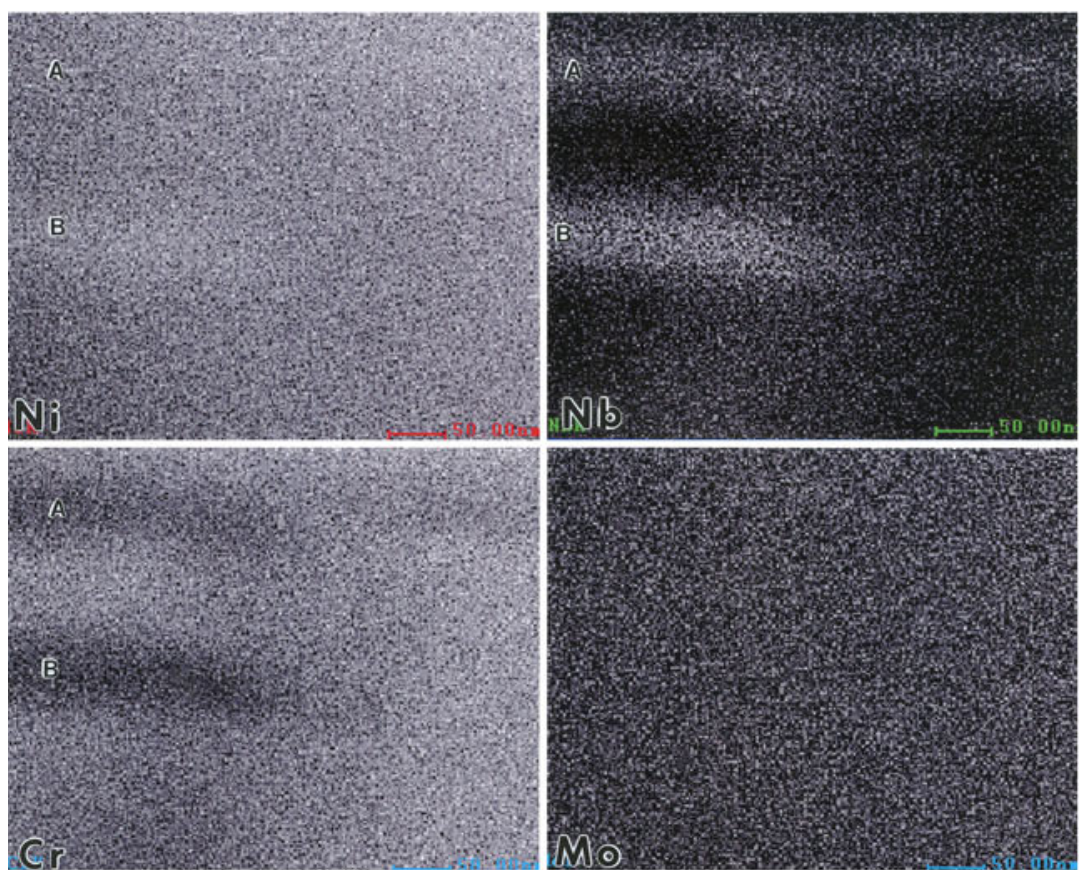

(d)

Fig. 11-TEM analysis sequence for $\mathrm{Ni}_{3} \mathrm{Nb}$ precipitate platelet identification/verification. (a) Bright-field image for (111) coincident precipitate platelets at A and B, with thickness denoted $t$. (b) SAED pattern corresponding to (a) showing [011] trace direction $(T)$ and operating reflection $(\mathbf{g}=[020])$ in a [100] zone axis pattern. Note in (a) the precipitate at $t$ intersects another out-of-contrast platelet. (c) The corresponding EDS spectrum for (a). (d) Elemental mapping sequence for (c) showing $\mathrm{Nb}$ at $\mathrm{A}$ and $\mathrm{B}$ precipitate platelets in (a). Weak Ni just above the background is also noticed. 


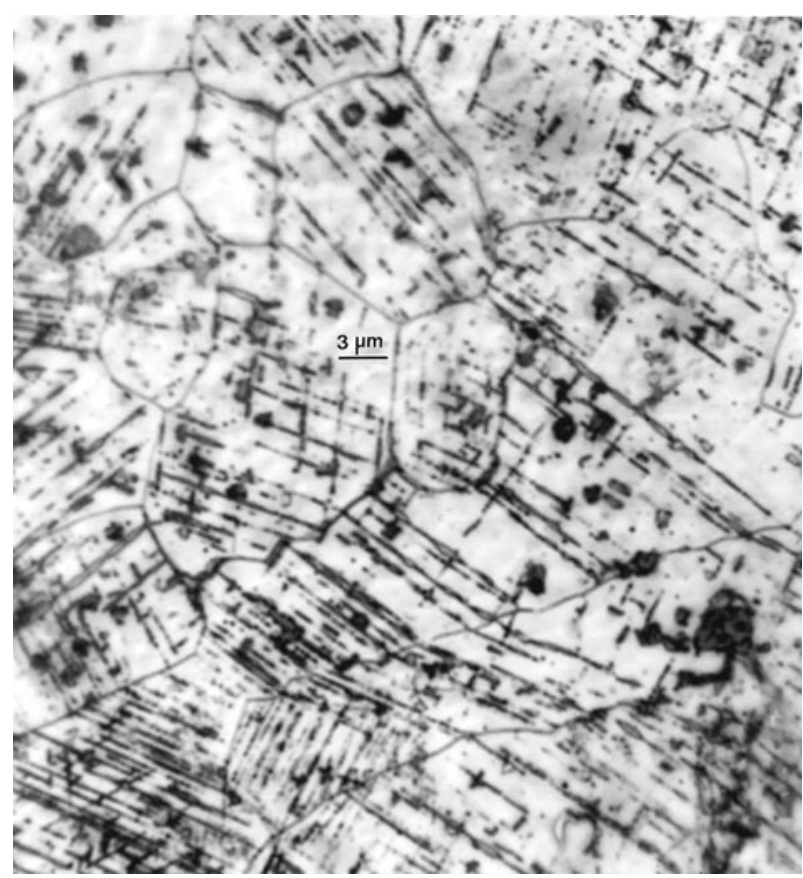

Fig. 12-Special $\mathrm{OM}$ image showing $\mathrm{Ni}_{3} \mathrm{Nb}\{111\}$ plane coincident precipitates in the equiaxed grain structure in a horizontal plane section along a cylindrical specimen built by EBM. Some GB precipitates are also noticed.

that the rectangular precipitate $(\mathrm{A})$ intersecting another, thinner precipitate plate, has a thickness $(t)$ of $\sim 50 \mathrm{~nm}$. The precipitate is coincident with the (111) planes in the (100) thin section (inclined $\sim 54$ deg to the (100) crystal surface plane) characterized by the $[01 \overline{1}]$ trace $(T)$ direction, also shown in the coincident SAED pattern in Figure 11(b). The operating vector, g, in Figure 11(b) is [020] and provides the diffraction contrast for the precipitates along [011] , denoted A and B in Figure 11(a). The precipitates, A and B in Figure 11(a), have slightly different diffraction contrasts, and they also exhibit complex, internal structure. Consequently, the X-ray signal is correspondingly similar in terms of X-ray photon counts, and this is illustrated along with the elemental X-ray maps in Figure 11(d). The precipitate positions indicated by A and $\mathrm{B}$ in the bright-field image of Figure 11(a) are similarly indicated in the maps in Figure 11(d). There is only weakly notable Ni above the $\mathrm{Ni}$ background for the $\mathrm{B}$ precipitate, while both $\mathrm{A}$ and $\mathrm{B}$ exhibit $\mathrm{Nb}$ only in the precipitates (A and $\mathrm{B}$ ), and predominantly in $\mathrm{B}$. There is $\mathrm{Cr}$ depletion in the precipitate platelets (A and B) as expected, while the Mo map illustrates a weakly uniform distribution.

Figure 12 illustrates an area in the horizontal plane normal to the build direction in a location within an EBM-fabricated cylinder, where the beam scanning or thermal environment caused the regular, columnar $\mathrm{Ni}_{3} \mathrm{Nb}$ arrays shown in Figures 3 through 5 to become regularly precipitated along the $\{111\}$ planes in continuous (linear) crystallographic arrays. This microstructure is a variance of the irregular features shown in Figure 6(a), but reinforces the propensity of the $\mathrm{Ni}_{3} \mathrm{Nb}$ precipitate platelets to be organized within the grain

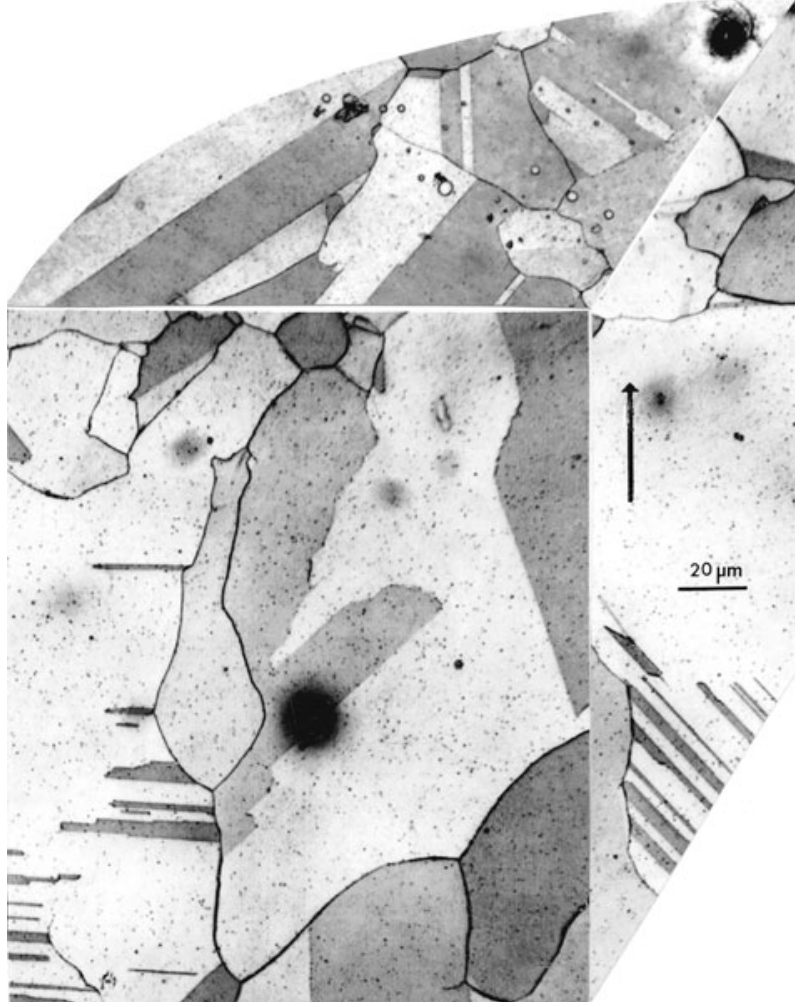

Fig. 13-OM 3-D-image reconstruction showing equilibrium, equiaxed grain structure in the hipped cylinder of EBM-fabricated alloy 625. Arrow indicates the build direction.

structures rather than the GBs, although some precipitation is observed along the columnar GBs in Figures 3 and 4 and in the corresponding horizontal plane GBs shown in Figure 6(a). These regular $\{111\}$ precipitate arrays shown in Figure 12 also convincingly and more macroscopically support the observations of $\{111\}$ coincidence illustrated collectively in Figures 8 through 10. Furthermore, Figures 6(a) and 12 attest to the generally equiaxed grain structure in the horizontal plane perpendicular to the build direction having an average grain size of $\sim 20 \mu \mathrm{m}$, commensurate with the grain column widths shown in Figures 3, 4, and 6(b).

\section{B. Structural and Microstructural Characterization of Hipped Cylinders}

The HIPed cylinders, as described earlier, were effectively annealed at roughly 80 pct of the melting temperature for 4 hours. This temperature and treatment were sufficient to affect recrystallization and grain growth and other prominent microstructural changes, and these are implicit in the corresponding cylindricalsection, 3-D reconstruction shown in Figure 13, which represents a single electroetch with phosphoric acid described in Section II-B. In contrast to the columnar architecture arrays of $\mathrm{Ni}_{3} \mathrm{Nb}$ precipitate platelets shown in Figures 3, 4, and 7 for the as-fabricated cylindrical components, Figure 13 illustrates an equiaxed grain structure in both the horizontal and vertical planes, 


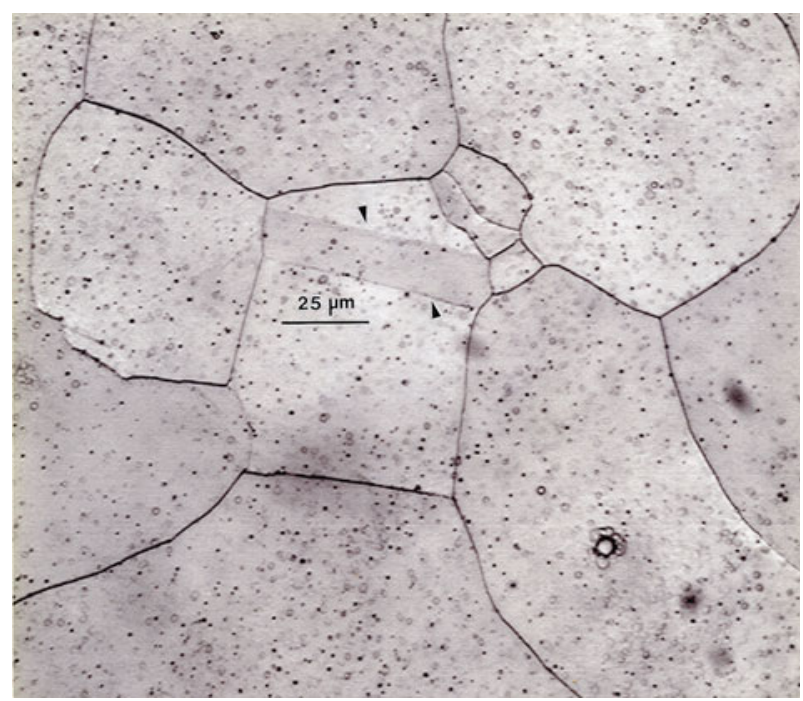

Fig. $14-\mathrm{OM}$ of specially etched (phosphoric + hydrochloric acid) horizontal section, as in Fig. 13, showing globular precipitates and exaggerated GB etching.

although there were a few elongated grains along the build direction for vertical planes as well. These grain structures contain a significant fraction of annealing twins as an indication of more equilibrium structures in contrast to the nonequilibrium precipitate architectures in the as-fabricated EBM components. It is also notable that the $\mathrm{Ni}_{3} \mathrm{Nb}$ precipitate platelet columns have apparently dissolved, and while the vertical plane grain structures exhibit some elongation (Figure 13), the columnar grains were reorganized by recrystallization, grain growth, and microstructural reorganization, including dissolution of the $\mathrm{Ni}_{3} \mathrm{Nb}$ precipitate platelet columns. The grain sizes, including the annealing twins, vary over a wide range (Figure 13) and average $\sim 50 \mu \mathrm{m}$ in contrast to the as-fabricated component grain diameters of $\sim 20 \mu \mathrm{m}$ in the horizontal reference plane and $\leq 500-\mu \mathrm{m}$ long grain columns with no annealing twins. Figure 13 also illustrates recognizable porosity similar to the as-fabricated specimens, as shown in Figure 6(b). This is an indication that the HIP anneal did not significantly alter the original porosity.

The contrast between the 3-D composition views in Figures 4 and 7 for the EBM-fabricated cylindrical builds, and the hipped/annealed cylinders in Figure 13, is essentially and conceptually identical to the microstructural variations between EBM-fabricated builds and the same builds after high-temperature annealing for a Co-base superalloy. ${ }^{[17]}$ In the Co-base alloy, columnar architectures composed of $\mathrm{Cr}_{23} \mathrm{C}_{6}$ precipitates with $\sim 2$ $\mu \mathrm{m}$ array spacings similar to those in the present work were annihilated after an annealing treatment, and the microstructure became an equiaxed, equilibrium grain structure containing a propensity of annealing twins similar to Figure 13 . $\mathrm{The} \mathrm{Cr}_{23} \mathrm{C}_{6}$ re-precipitated primarily on the equiaxed GBs, but not on the annealing twin boundaries (in the annealed Co-base superalloy ${ }^{[17]}$ ), because at the elevated equilibrium temperature, the coherent twin boundary free energy for the $\mathrm{Co}-\mathrm{Cr} \mathrm{fcc}$ structure was less than a factor of 20 of the GB free energy

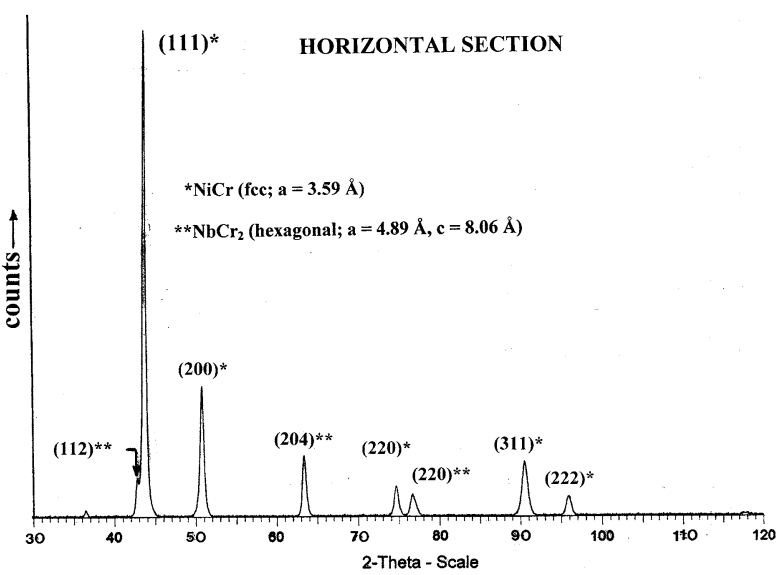

(a)

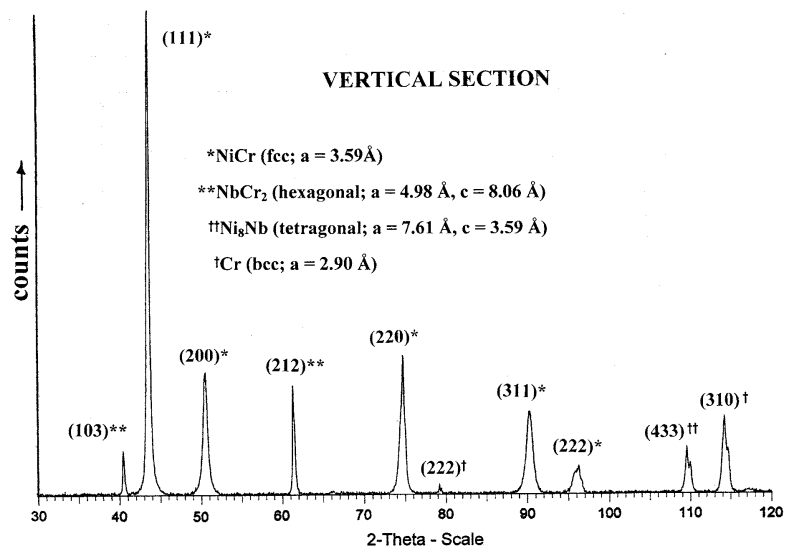

(b)

Fig.15-XRD spectra representing (a) the horizontal reference plane section and $(b)$ the vertical reference plane section in the 3-D composite in Fig. 13 for the hipped (annealed) alloy 625-fabricated (EBM) cylinders.

and, therefore, energetically unfavorable for precipitate nucleation. ${ }^{[27]}$ In addition, the low stacking-fault free energy for the fcc $\mathrm{Co}-\mathrm{Cr}$ promoted a profusion of intrinsic stacking faults within the grains, as observed by TEM. ${ }^{[17]}$

Figure 14 shows a horizontal section view similar to the 3-D-horizontal section view in Figure 13, but with a modified etch to reveal the homogeneous distribution of globular precipitates in contrast to the crystallographic precipitate arrays for the as-fabricated components shown in Figures 3, 4, and 12. The etching specific to Figure 14 also shows enhanced etching of the GBs relative to the coherent twin boundaries (arrows), but not revealing a propensity of GB precipitates relative to the grain interiors. This enhanced GB etching is a consequence of the much lower twin boundary free energy $v s$ the GB free energy. The ratio of twin boundary free energy/GB free energy $\left(\gamma_{t b} / \gamma_{g b}\right)$ for INCONEL 600 (Ni-Cr-Fe) or $\mathrm{Ni}-20 \mathrm{Cr}$ is $\sim 0.023$ at $1333 \mathrm{~K}\left(1060^{\circ} \mathrm{C}\right)$, and the corresponding $\mathrm{GB}$ free energy is $\sim 750 \mathrm{~mJ} / \mathrm{m}^{2}$. ${ }^{[27]}$ This is $\sim 333 \mathrm{~K}\left(60{ }^{\circ} \mathrm{C}\right)$ below the hipping temperature [1393 $\left.\mathrm{K}\left(1120^{\circ} \mathrm{C}\right)\right]$.

Figure 15 shows the XRD analysis corresponding to the horizontal and vertical reference planes, respectively, 
in the annealed (hipped) cylindrical components, as represented typically in Figure 13. In contrast to the precursor powder (Figure 5(a)) and the as-fabricated horizontal and vertical section reference planes (Figures 5(c) and (d)), the [200] horizontal and [220] vertical textures, respectively, are replaced by a uniform [111] horizontal and vertical plane texture for the annealed, equiaxed microstructure with annealing twins (Figures 13 and 14). There is some detectable $\mathrm{Ni}_{8} \mathrm{Nb}$ (tetragonal: $a=0.76 \mathrm{~nm}, c=0.36 \mathrm{~nm}$; space group: $\mathrm{P}(0))$ in the vertical section, indicating a nearly complete solutionizing of $\mathrm{Ni}-\mathrm{Nb}$ precipitates. However, each reference plane section shows the presence of an $\mathrm{NbCr}_{2}$ laves phase (hexagonal: $a=0.49 \mathrm{~nm}, c=0.81 \mathrm{~nm}$; space group: $P 631 \mathrm{mmc}$ ), which characterizes the globular precipitates shown in Figure 14. In addition, there is a prominent $\mathrm{Cr}$ (310) peak in the vertical section XRD in Figure 15(a) (bcc: $a=0.29 \mathrm{~nm}$; space group: Im$3 m$ ). A globular laves phase was observed in INCONEL 718 weld metals (including electron beam welded components) by Radakrishna et al. ${ }^{[29]}$ Laves phase brittle, intermetallic, topologically close-packed (TCP) phase with hexagonal structure is normally detrimental to mechanical properties at room temperature.

Scanning electron microscopy (SEM) combined with EDS showed some segments of $\mathrm{Nb}$ prominence within the GBs, while the X-ray signal from the globular precipitates within the grains (Figure 14) exhibited erratic elemental prominence because of the large etched regions surrounding the precipitates similar to those regions surrounding the $\gamma^{\prime \prime}$ precipitate platelets, as illustrated in Figures 8 and 9(c).

Similar to the more dependable elemental mapping of $\gamma^{\prime \prime}$ precipitate platelets, as illustrated in Figure 11(d), the globular (laves) precipitates exhibited prominent $\mathrm{Cr}$ in EDS maps, as illustrated in the TEM image and EDS maps in Figure 16. As shown in Figure 16, many precipitates illustrated facets and regular crystalline forms, and some precipitates exhibited singular $\mathrm{Cr}$ maps apparently corresponding to the $\mathrm{Cr}$ (310) peak in Figure 15(a) (vertical section XRD spectrum). Figure 16(a) shows a small annealing twin with associated precipitates, while Figure 16(b) shows a magnified view of a precipitate in Figure 16(a) (arrow). Figure 16(c) illustrates the corresponding $\mathrm{Cr}$ map for Figure 16(b). Figures 16(d) and (e) show a precipitate aggregate and corresponding Cr EDS map, respectively. Several regular crystallographic precipitates are shown in Figure 16(f) near a GB, which exhibits complex ledge structure. This complex, high-energy structure could cause the selective GB etching illustrated in Figure 14.

The lack of a recognizable $\mathrm{Nb}$ signal for the precipitates in Figure 16 may be due, in part, to the weak elemental spectra in contrast to the elemental $\mathrm{Cr}$ particle spectra. The Ni stoichiometry is also not above the background $\mathrm{Ni}$ and therefore does not create recognizable contrast maps. In addition, the presence of $\mathrm{Ni}_{8} \mathrm{Nb}$ in the XRD pattern in Figure 15 (vertical section) could be an indication of $\mathrm{Nb}$ depletion as a consequence of the HIP-anneal treatment for the EBM-fabricated components. However, we have no specific thermo.-kinetic or fundamental energy minimization data to support this suggestion, except to note that this composition is at the edge of the Ni-rich region in the $\mathrm{Ni}-\mathrm{Nb}$ phase diagram at the HIP-anneal temperature $\left[1393 \mathrm{~K}\left(1120{ }^{\circ} \mathrm{C}\right)\right] .^{[7]}$

Unlike many Ni-base alloys subjected to various thermomechanical treatments, there were very few examples of stacking fault microstructures ${ }^{[30]}$ in the EBM-fabricated components (Figures 9 through 11) as well as the hipped and hipped and aged [811 $\left.\mathrm{K}\left(538^{\circ} \mathrm{C}\right)\right]$ components, even though the room temperature stacking-fault free energy for alloy 625 is estimated to be $\sim 35 \mathrm{~mJ} / \mathrm{m}^{2}{ }^{[27]}$ Figure 16 shows numerous examples of laves precipitates, which exhibit very prominent strain contrast fringe arrays when the foils were tilted in the TEM. In addition, all of the precipitates (Figure 16) exhibited associated dislocations or dislocation arrays, some extending long distances from the precipitate $/ \gamma$ interface and some exhibiting dislocation generation at the precipitate $/ \gamma$ interface. Figures 17 (a) and (b) illustrate typical examples of these dislocation/precipitate phenomena. In addition, because of the nature of dislocation generation and propagation on the $\gamma-\{111\}$ planes, the precipitates appear to be coincident with the \{111\} planes: (001) precipitate (laves) \| (111). In Figure 17(a), complex dislocation loops generated at the precipitate $/ \gamma$ interface are associated with two dipole network arrays on (111). Note the dislocations ending on the (110) surface plane along the $[\overline{1} 10]$ trace coincident with the (110) SAED pattern insert. Figure 17 (b) shows precipitates in $\{111\}$ planes characterized by intersecting (perpendicular) trace directions $[022]$ and $[0 \overline{2} 2]$ corresponding to intersecting $(11 \overline{1})$ and (111) planes, each making an angle of $\sim 54 \mathrm{deg}$ with the (100) grain surface shown by the SAED pattern insert. Dislocation emission and propagation on these planes is prominently demonstrated in Figure 17(b).

While, as noted, stacking fault fringe contrast was only occasionally observed for specific tilt angles in the TEM, there were related, low-stacking-fault-energyrelated microstructural features. Figures 17(c) and (d) illustrate typical examples. Figure 17(c) shows a precipitate, an 11-fold dissociated dislocation array (arrow), and a complex GB structure composed of ledges and dislocations similar to Figure 16(f). These GB structures were dominant representations of the GBs in the hipped and hipped plus tensile test aging at $811 \mathrm{~K}\left(538^{\circ} \mathrm{C}\right)$. Figure 17(d) shows pairs of partial dislocation dipoles or a pileup of dissociated dipoles, which, like the dissociated dislocation array in Figure 17(c), is associated with low-stacking-fault free energy. ${ }^{[30]}$

\section{Analysis and Comparison of As-Fabricated and Hipped Mechanical Properties: Hardness and Tensile Tests}

The average microindentation hardness (HV) for the precursor powder was $2.6 \mathrm{GPa}$, as noted earlier in reference to Figure 3, while the horizontal and vertical reference plane microindentation hardnesses (HV) were measured to be 2.8 and $2.5 \mathrm{GPa}$, respectively, for the as-fabricated cylindrical components (Figure 3). In contrast to these microindentation hardness measurements, the hipped (annealed) cylindrical components exhibited 

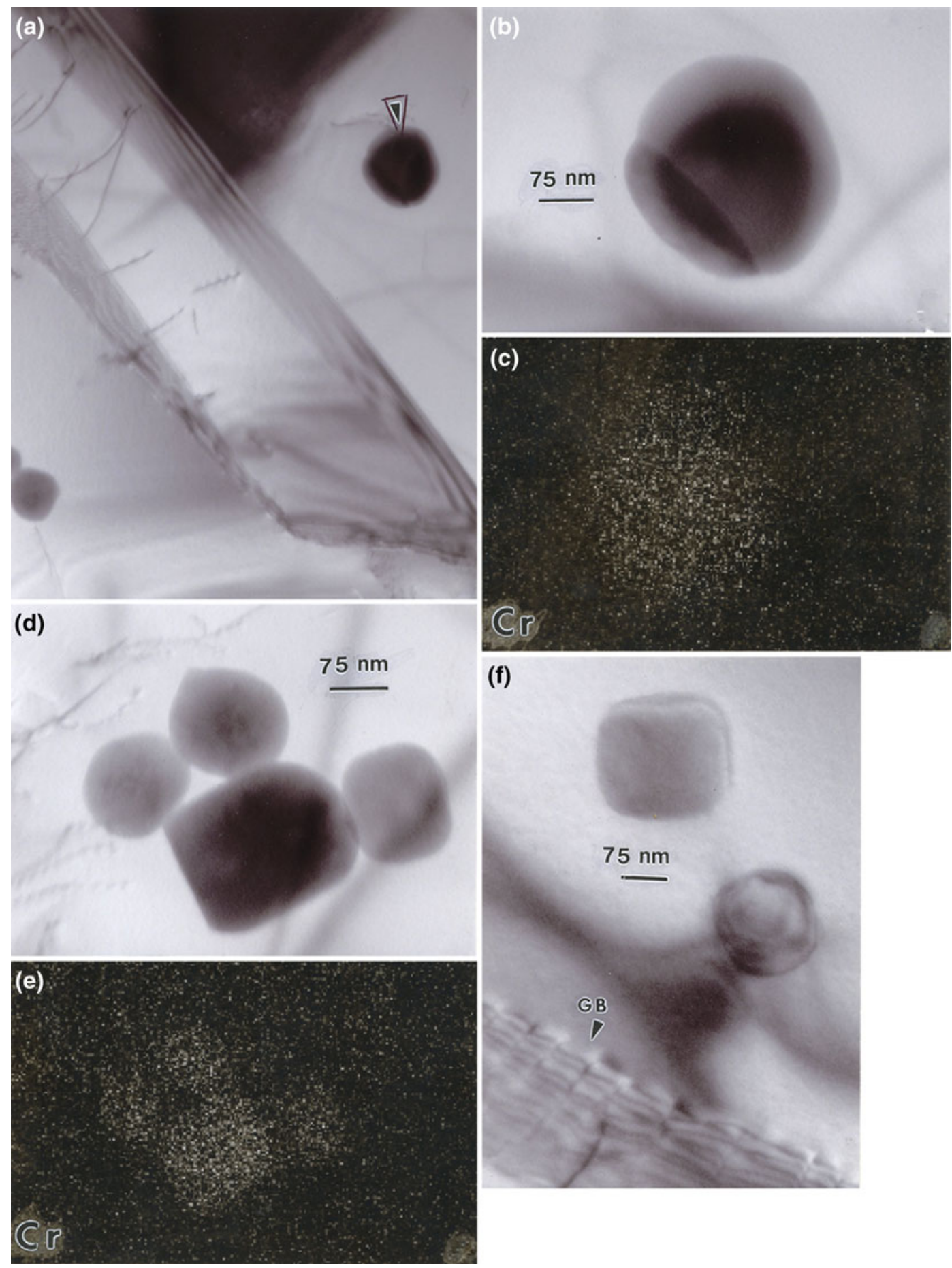

Fig. 16-Examples of laves $\left(\mathrm{NbCr}_{2}\right)$ precipitates in Fig. 14 observed in the TEM. $(a)$ and $(b)$ show precipitate and enlargement (arrow), while $(c)$ illustrates the corresponding $\mathrm{Cr}$ map for (b). (d) and (e) Precipitate cluster and associated $\mathrm{Cr}$ map, respectively. $(f)$ Precipitates near a complex structural GB. The larger precipitate appears to be $\sim 50-\mathrm{nm}$ thick. Note that the precipitate particle in (b) is a bicrystal.

average values (HV) of 2.2 and $2.1 \mathrm{GPa}$ for the horizontal and vertical reference planes, respectively, as illustrated in the 3-D composition of Figure 13, or a roughly 17 pct decrease from the EBM-fabricated component hardness. This is generally consistent with the overall microstructure variations (compare Figures 3 and 13).
Rockwell C-scale hardness (HRC) averages for the EBM-fabricated components, and these components following hipping, as well as samples tested in tension at $811 \mathrm{~K}\left(538^{\circ} \mathrm{C}\right)$, are listed in Table II along with nominal wrought products and the corresponding Vickers microindentation hardness values (HV in units of GPa). The Rockwell C-scale (HRC) hardness variation 

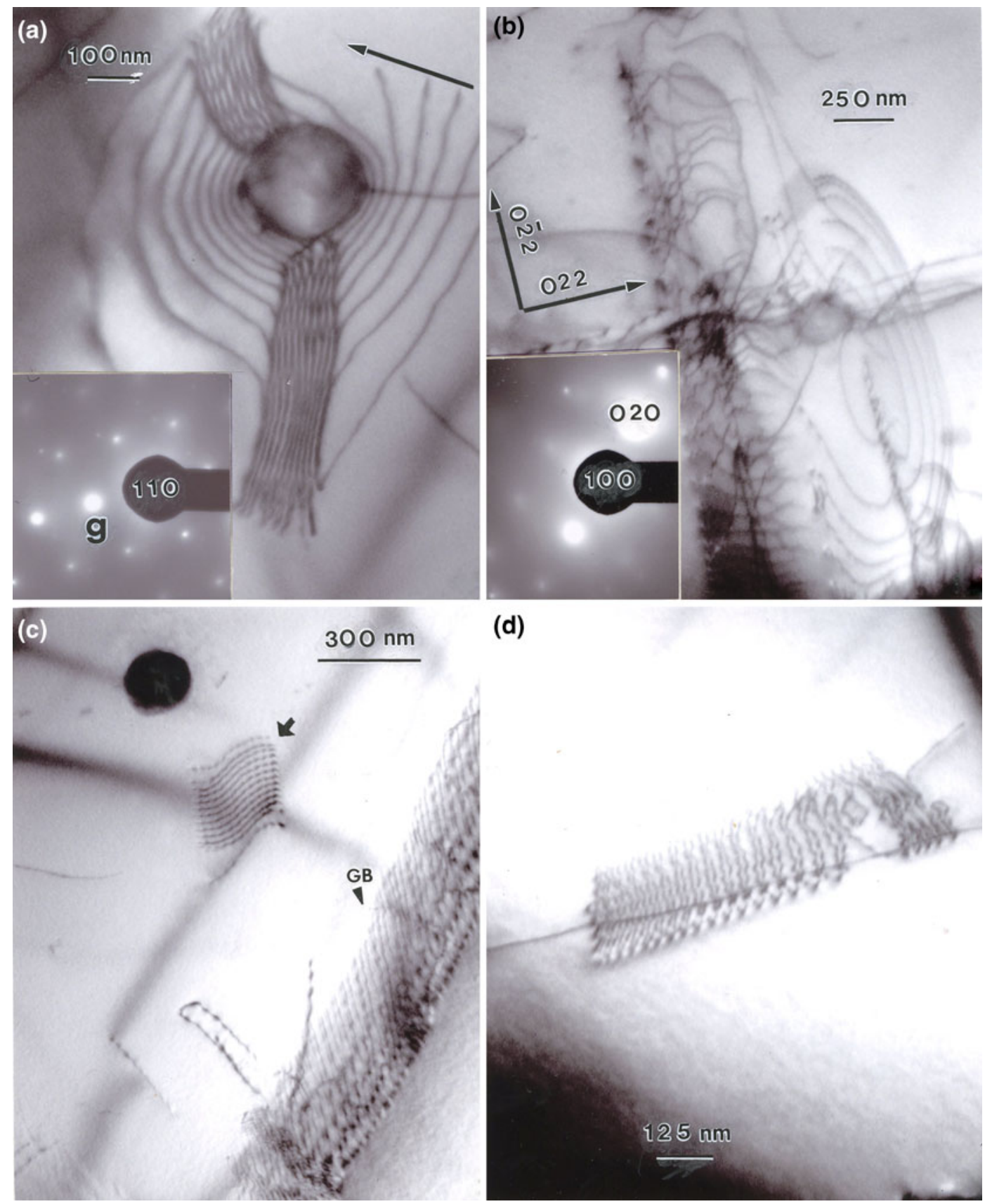

(d)

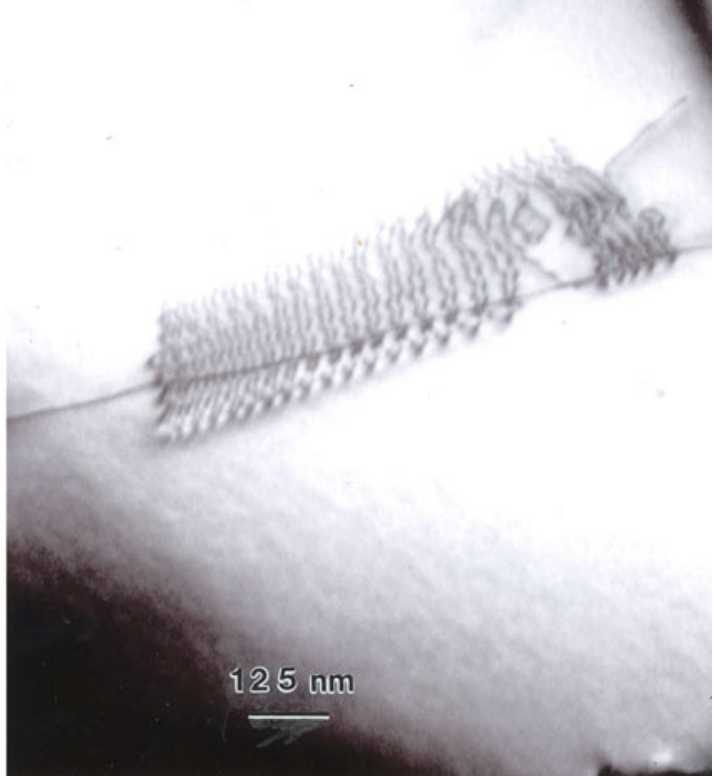

Fig. 17-TEM images of precipitate/dislocation microstructures in the vertical reference plane for a hipped $+811 \mathrm{~K}\left(538{ }^{\circ} \mathrm{C}\right)$ exposure (in the grip region of a tensile specimen). (a) and (b) Dislocation arrays associated with precipitates on $\{111\} \gamma$ planes. The operating reflection, $\mathbf{g}$, in (a) was [111]. (c) and (d) Arrays of dissociated partial dislocations on $\{111\}$ planes (arrow in (c)). Note the complex GB structure in (c).

between cold-rolled wrought and annealed wrought alloy 625 is 50 pct, in contrast to nearly the same reduction percentage for the EBM-fabricated cylinders and the as-fabricated and hipped and as-fabricatedhipped and additional tensile heating at $811 \mathrm{~K}\left(538^{\circ} \mathrm{C}\right)$. Note that the tensile-heated $\left[811 \mathrm{~K}\left(538^{\circ} \mathrm{C}\right)\right]$ samples were measured (hardness) and microstructurally examined in the grip region and not in the plastically deformed, necked region; therefore, they represent a small temperature (annealing) increment over the HIP anneal at $1393 \mathrm{~K}\left(1120^{\circ} \mathrm{C}\right)$. Additionally, it can be noted that the cold-rolled (as-fabricated) wrought alloy $625 \mathrm{HRC}$ value is also roughly 65 pct greater than the corresponding EBM-fabricated value in contrast to roughly 60 pct for the annealed-wrought product and the EBM as-fabricated and hipped product.

In contrast to the hardness variations between the wrought-processed and EBM-processed alloy 625 illustrated in Table II, there is a corresponding 60 pct drop in yield stress for cold-rolled and annealed wrought material, but only a 20 pct drop in yield stress $(0.2 \mathrm{pct}$ offset) for the EBM-fabricated vs hipped product, 
Table II. Mechanical Properties of EBM and Wrought Alloy 625

\begin{tabular}{|c|c|c|c|c|c|}
\hline Material & $\mathrm{HV}^{*}(\mathrm{GPa})$ & $\mathrm{HRC} * *$ & YS ksi (GPa) & UTS ksi (GPa) & Elongation (Pct) \\
\hline Precursor powder & 2.6 & - & - & - & - \\
\hline Cold-worked wrought ${ }^{\dagger}$ & - & 40 & $160(1.10)$ & - & 18 \\
\hline Annealed wrought & - & 20 & $65(0.45)$ & $130(0.89)$ & 44 \\
\hline As-fabricated (EBM) & $2.8 / 2.5^{\S}$ & 14 & $60(0.41)$ & $109(0.75)$ & 44 \\
\hline EBM fabricated + HIP & $2.2 / 2.1^{\S}$ & 8 & $48(0.33)$ & $112(0.77)$ & 69 \\
\hline Wrought at $811 \mathrm{~K}\left(538{ }^{\circ} \mathrm{C}\right)$ & - & 18 & $41(0.28)$ & $120(0.83)$ & 50 \\
\hline As-fabricated $(\mathrm{EBM})$ at $811 \mathrm{~K}\left(538^{\circ} \mathrm{C}\right)$ & $2.6 / 2.8^{\S}$ & 14 & $44(0.30)$ & $86(0.59)$ & 53 \\
\hline EBM fabricated HIP at $811 \mathrm{~K}\left(538{ }^{\circ} \mathrm{C}\right)$ & $2.3 / 2.2^{\S}$ & 6 & $34(0.23)$ & $89(0.61)$ & 70 \\
\hline
\end{tabular}

Note: YS -0.2 pct offset yield stress, and UTS - ultimate tensile strength.

*Vickers (diamond) microindentation hardness (100 g load).

**Rockwell C-scale hardness (150 kg load) (average).

${ }^{\dagger}$ Cold-worked (extruded) bar stock tensile tested at room temperature [ $\left.293 \mathrm{~K}\left(20{ }^{\circ} \mathrm{C}\right)\right]$.

${ }^{\ddagger}$ Annealed $1 \mathrm{~h}$ at $1573 \mathrm{~K}\left(1250{ }^{\circ} \mathrm{C}\right)$ and tensile tested at room temperature.

${ }^{\S}$ Horizontal plane/vertical plane hardness.

"EBM-fabricated cylinders machined into tensile specimens and hipped, as described in the text.

although the EBM alloy 625 variance in the UTS increases by $\sim 3$ pct. As shown in Table II, the wrought alloy 625 elongation increases by 59 pct from the coldrolled to annealed condition, in contrast to a $57 \mathrm{pct}$ increase from EBM-fabricated to annealed (hipped) material. However, there is a 57 pct elongation increase between the annealed, wrought alloy 625 in contrast to the EBM-fabricated and annealed (hipped) alloy 625. Corresponding variances, especially elongation, are similarly observed for the additional tensile temperature exposure at $811 \mathrm{~K}\left(538{ }^{\circ} \mathrm{C}\right)$, as shown in Table II.

The significant increase in elongation for the annealed, EBM-fabricated alloy 625 vs the annealed, wrought alloy 625 (69 pct vs 44 pct in Table II), along with the corresponding $0.45 \mathrm{GPa}$ vs $0.33 \mathrm{GPa}$ yield strength reduction (Table II), is an indication of the microstructural variations implicit on comparing the EBM-fabricated alloy 625 product microstructures and microstructural architecture in Figure 4 with the correspondingly hipped (annealed) product in Figure 13.

Figure 18(a) shows the associated fracture surface features observed in the SEM at different magnifications, corresponding to $\sim 44$ pct elongation to fracture for an EBM-fabricated tensile test specimen. The fracture surface structure shows a characteristic ductile-dimple behavior with a mean, equiaxed dimple diameter of $1.4 \mu \mathrm{m}$, roughly half the size of the $\mathrm{Ni}_{3} \mathrm{Nb}$ precipitate array spacing (Figures 3 ) in the horizontal reference plane normal to the tensile axis (and the EBM build direction).

These relatively small dimple diameters (Figure 18(a)) are considerably smaller than those observed for EBMfabricated Ti-6Al-4V $(4.4 \mu \mathrm{m})$, which, in contrast to larger ductile dimple diameters for wrought Ti-6Al-4V, were associated with a 58 pct increase in ductility over the wrought product. ${ }^{[28]}$ This feature may apply in the present case for EBM alloy 625 vs wrought, although comparative ductile dimple diameter data are not available for wrought alloy 625 . However, as noted in Figure 18(b), representing the roughly 69 pct elongation to failure for the EBM-fabricated and hipped (annealed) component, the ductile dimple diameters shown in
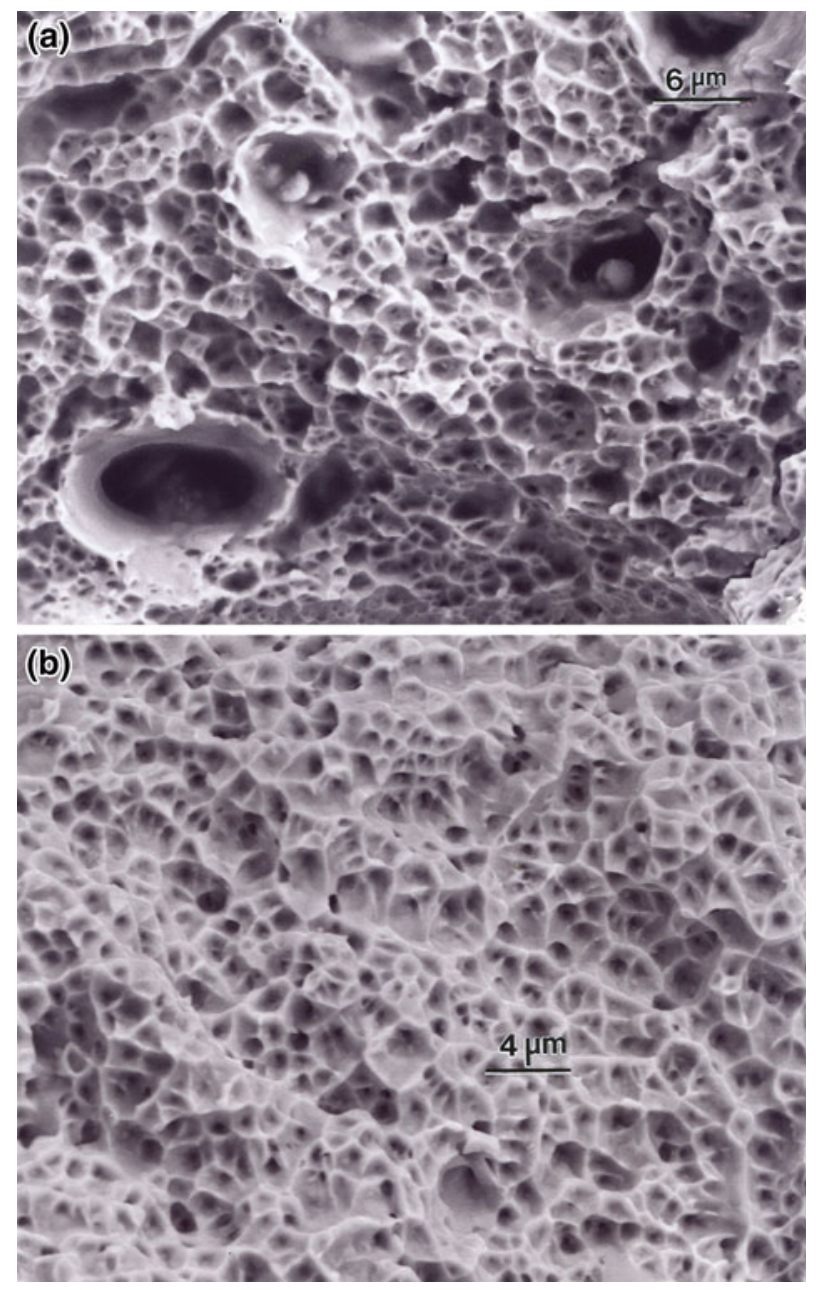

Fig. 18 - SEM fracture surface structures for (a) EBM as-fabricated tensile sample and (b) EBM-fabricated and hipped (annealed) cylindrical component.

Figure 18(b) $(\sim 1.5 \mu \mathrm{m}))$ are the same as those shown in Figure 18(a). In contrast to recent work on an EBMfabricated Co-base superalloy, where the fracture-surface 
ductile dimples exhibited a regular, cubelike (orthogonal) array exactly matching the $2-\mu \mathrm{m} \mathrm{Cr}_{23} \mathrm{C}_{6}$ columnar arrays, the ductile dimples in Figures 18(a) and (b) are more random arrays, slightly smaller than the $\mathrm{Ni}_{3} \mathrm{Nb}$ precipitate arrays (spaced $\sim 2 \mu \mathrm{m}$ in Figure 3). This feature is possibly influenced by the precipitation in both the EBM-fabricated samples (Figure 3) and these same samples following hipping at $1120{ }^{\circ} \mathrm{C}$ (Figure 14).

It might be noted, as evidenced by small porosities in the as-fabricated EBM alloy 625 shown in Figure 6(b) and similar porosity features shown in Figure 13, that the exceptional elongation improvement in the hipped alloy 625 samples $v s$ the as-fabricated samples is due more to the notable change in the microstructure. This change includes annihilation of the $\mathrm{Ni}_{3} \mathrm{Nb}$ precipitate columnar architecture and columnar grain structure, and the development of a more equilibrium and equiaxed grain structure, with homogenous $\mathrm{NbCr}_{2}$ laves precipitation in the grain interiors. As illustrated in Figure 17, these precipitates, even after HIP treatment, produced copious arrays of dislocations, and tensile straining would be expected to produce extensive slip, accommodating the extreme elongations noted in Table II. This phenomenon is contrary to the usual degradation of mechanical properties attributed to laves phase, as noted earlier.

\section{SUMMARY AND CONCLUSIONS}

The EBM fabrication of primarily cylindrical components along with some rectangular components from prealloyed INCONEL $625(66 \mathrm{Ni}, 21 \mathrm{Cr}, 9 \mathrm{Mo}, 4 \mathrm{Nb}$; nominal weight percent) powder creates nearly fully dense $\left(8.4 \mathrm{~g} / \mathrm{cm}^{3}\right)$ monoliths having a Ni-Cr $(\gamma)$ fcc matrix. More importantly, the unique, orthogonal $(x-y)$ electron beam melt scan produced columnar arrays (or architecture) of thin, crystallographically coincident $\gamma^{\prime \prime}$ (bct) $\mathrm{Ni}_{3} \mathrm{Nb}$ precipitates. These columnar precipitate arrays were parallel to the build direction and the cylinder axis, and also parallel to columnar grains having a [200] texture along this axis. The bet $\gamma^{\prime \prime}$ precipitate platelets were coincident with the fcc $\gamma\{111\}$ planes: (010) $\gamma^{\prime \prime} \|$ (111) $\gamma$. The columnar $\gamma^{\prime \prime}$ precipitate platelet arrays assumed an irregular orthogonal $(x-y)$ geometry spaced $\sim 2 \mu \mathrm{m}$ in the horizontal reference plane, consistent with the spacing of carbide precipitate columnar arrays in a Co-base alloy (ASTM-F75) ${ }^{[17]}$ fabricated by EBM using the same electron beam melt scan parameters as employed in the present work.

HIPing of the EBM as-fabricated cylinders at $1393 \mathrm{~K}$ $\left(1120^{\circ} \mathrm{C}\right.$ ) for 4 hours dissolved the $\gamma^{\prime \prime}$ (bct) $\mathrm{Ni}_{3} \mathrm{Nb}$ precipitate columnar architecture and recrystallized the [200] oriented columnar grains (which measured $\sim 20 \mu \mathrm{m}$ in diameter and $\leq 500 \mu \mathrm{m}$ in length along [200]) to form an equiaxed grain structure, containing coherent $\{111\}$ annealing twins, with an average diameter of $\sim 50 \mu \mathrm{m}$. These equiaxed grains contained mostly a homogeneous distribution of $\mathrm{NbCr}_{2}$ - laves phase (hexagonal) globular precipitates. While there were almost no stacking faults, the microstructure exhibited complex dislocation arrays, including dipole arrays, emitted from the laves precipitates on $\{111\}$ planes, as well as dissociated partial dislocation arrays on $\{111\}$, indicative of low stackingfault free energy. Essentially all of the precipitates exhibited TEM tilt-sensitive strain contours, and all illustrated dislocation emission or attachment of some kind. In addition, the GB structure exhibited a noticeably high energy, as evidenced by selective etching at the GBs, and their structures were characterized by a complex arrangement of ledges and dislocations.

These two contrasting microstructure/microstructural architecture regimes (as-fabricated (EBM) components $v s$ the as-fabricated and hipped components) exhibited correspondingly contrasting mechanical properties. For example, the $\gamma^{\prime \prime}$ (bct) columnar precipitate architecture in the as-fabricated components exhibited a Vickers microindentation hardness varying from 2.8 to $2.5 \mathrm{GPa}$ in the corresponding cylinder horizontal and vertical reference planes. This microindentation hardness was reduced to 2.2 and $2.1 \mathrm{GPa}$ in the horizontal and vertical reference planes for the hipped cylinder components with an equiaxed grain structure containing $\mathrm{NbCr}_{2}$ (laves) precipitates. Correspondingly, the as-fabricated, tensile-tested cylinders had a yield stress of $0.41 \mathrm{GPa}$ and a UTS of $0.75 \mathrm{GPa}$ in contrast to 0.45 and $0.89 \mathrm{GPa}$ for annealed, wrought alloy 625 . The corresponding elongation for the EBM-fabricated alloy 625 matched that for annealed, wrought alloy 625 at 44 pct. However, the corresponding tensile data for the as-fabricated (EBM) and hipped cylinders exhibited a yield stress of $0.33 \mathrm{GPa}$, a UTS of $0.77 \mathrm{GPa}$, and an elongation of 69 pct. The extraordinary elongation in the EBM-fabricated and hipped cylinders (57 pct increase over un-hipped material) was observed to be more related to the annealed microstructure (equiaxed $50-\mu \mathrm{m}$ grains containing $\mathrm{NbCr}_{2}$ laves precipitates) than the closing of bubbles and small pores, although there was a roughly 1 pct decrease in porosity between the asfabricated and hipped samples (a measured density increase from $\sim 8.4$ to $\sim 8.5 \mathrm{~g} / \mathrm{cm}^{3}$ ).

The tensile testing of EBM-fabricated cylinders at $811 \mathrm{~K}\left(538{ }^{\circ} \mathrm{C}\right)$ did not significantly alter the microindentation hardness from the EBM-fabricated cylinders tested at room temperature $\left[\sim 293 \mathrm{~K}\left(20^{\circ} \mathrm{C}\right)\right]$ (measured in the grip region), but the yield stress dropped from 0.33 to $0.30 \mathrm{GPa}$ and the UTS decreased by 23 pct. The corresponding elongation increased from 44 to 53 pct. Similarly, the EBM-fabricated and hipped cylinders when tensile tested at $811 \mathrm{~K}\left(538^{\circ} \mathrm{C}\right)$ also illustrated no significant microindentation hardness in the grip area, but the yield stress decreased from 0.33 to $0.30 \mathrm{GPa}$, while the UTS decreased from 0.77 to $0.61 \mathrm{GPa}$. However, the elongation only increased from 69 to 70 pct on comparing the as-fabricated + HIP cylinders tested at room temperature, in contrast to the same cylindrical specimens tested at $811 \mathrm{~K}\left(538{ }^{\circ} \mathrm{C}\right)$. By comparison, wrought alloy 625 tensile tested at $811 \mathrm{~K}$ $\left(538^{\circ} \mathrm{C}\right)$ exhibited a yield stress of $0.28 \mathrm{GPa}$, a UTS of $0.83 \mathrm{GPa}$, and an elongation of 50 pct (Table II).

The ductile dimple diameters measured on the fracture surfaces for both the EBM-fabricated and EBMfabricated + HIP components were essentially identical 
at $\sim 2 \mu \mathrm{m}$. This dimension matches dimple diameters for EBM-fabricated cylinders of a Co-base alloy tensile tested at room temperature. ${ }^{[17]}$ However, the dimples were not regular, orthogonal $(x-y)$ arrays matching the $\gamma^{\prime \prime}$ precipitate architecture in contrast to dimple arrays, matching the orthogonal carbide precipitate columnar architecture in Co-base, ASTM-F75 alloy. ${ }^{[17]}$

In contrast to more conventional Ni-base superalloys in cast and wrought forms, and with a variety of thermomechanical processing schedules, the EBM-fabricated and processed INCONEL 625 examined in this study demonstrated unusual microstructures and microstructural (columnar precipitate) architecture. These microstructural features were correlated with unique mechanical properties, especially elongations at room temperature, which exceeded worked wrought alloy 625 products by more than 283 pct and annealed, wrought alloy 625 products by 57 pct for EBM-fabricated and hipped (annealed) components (Table II). These unusual microstructure/microstructural architecture features in the EBM-fabricated and processed Ni-base (INCONEL 625) alloy illustrate the potential for EBMfabricated products with controlled microstructural architectures and their engineering applications.

\section{ACKNOWLEDGMENTS}

This research was supported, in part, by Mr. and Mrs. MacIntosh Murchison Endowed Chairs (LEM and RBW) as well as graduate research assistantships at the University of Texas at El Paso. We thank ARCAM AB-Sweden and Metals Technology, Inc. for technical support and services.

\section{REFERENCES}

1. J.M. Oblak and B.H. Kear: Trans. ASM, 1961, vol. 61, pp. 519-26.

2. R.M. Forbes Jones and L.A. Jackman: JOM, 1999, Jan., p. 27.

3. Superalloys, E.F. Bradley, ed., ASM INTERNATIONAL, Materials Park, OH, 1988.

4. Int. Symp. on Superalloys, ASM, Metals Park, OH, 1980.

5. B.H. Kear: Scientif. Am., 1986, No. 4, pp. 159-65 (see related articles in the same issue)

6. N.D. Souza, M.G. Ardakani, M. McLeah, and B.A. Shollock: Metall. Mater. Trans. A, 2000, vol. 31A, pp. 2877-85.

7. Nickel, Cobalt and Their Alloys, ASM INTERNATIONAL, Materials Park, OH, 2000.
8. R.C. Reed: The Superalloys: Fundamentals and Applications, Cambridge University Press, Cambridge, United Kingdom, 2006.

9. J.M. Silva, R.A. Claudio, A. Sousa, R. Brito, C.M. Branco, and J. Byrne: in Materials Science Forum, P.M. Vilarinho, ed., Trans. Tech Publications, Aedermannsdorf, Switzerland, 2006, vols. 514 516.

10. Solidification Technology, J.F. Burks, M.C. Flemings, and A.E. Gorum, eds., Brook Hill Publishing Co., New York, NY, 1974.

11. K.E. Eckelmeyer and R.W. Hertzberg: Metall. Trans., 1972, vol. 2, pp. 609-15.

12. J.A. Jackson and J.D. Hunt: Trans. AIME, 1966, vol. 236, pp. 1129-35.

13. E.R. Thompson and F.D. Lemkey: Trans. ASM, 1969, vol. 62, pp. $140-47$.

14. H.F. Merrick: Int. Symp. on Superalloys, ASM, Metals Park, OH, 1980 , p. 161.

15. D. Cormier, D. Harryson, and H. West: Rapid Prototyping J., 2004, vol. 10 (1), pp. 35-41.

16. S.M. Gaytan, L.E. Murr, F. Medina, E. Martinez, M.I. Lopez, and R.B. Wicker: Mater. Technol.: Adv. Perform. Mater., 2009, vol. 24 (9), pp. 180-88.

17. S.M. Gaytan, L.E. Murr, E. Martinez, J.L. Martinez, B.I. Machado, D.A. Ramirez, F. Medina, S. Collins, and R.B. Wicker: Metall. Mater. Trans. A, 2010, vol. 41A, pp. 3216-27.

18. D.A. Ramirez, L.E. Murr, S.J. Li, Y.X. Tian, E. Martinez, J.L. Martinez, B.I. Machado, S.M. Gaytan, F. Medina, and R.B. Wicker: Mater. Sci. Eng. A, 2011, vol. 528A, pp. 5379-86.

19. R. Mehrabian, B.H. Kear, and M Cohen: Rapid Solidification Processing, Claitor's Publishing Division, Baton Rouge, LA, 1978.

20. R.J. Patterson, II, A.R. Cox, and E.C. Vanreuth: J. Met., 1980, vol. $32(9)$, pp. $34-41$

21. M.A. Meyers, R.B. Gupta, and L.E. Murr: J. Met., 1981, vol. 33 (10), pp. 21-27.

22. D.A. Ramirez, L.E. Murr, E. Martinez, D.H. Hernandez, J.L. Martinez, B.I. Machado, F. Medina, R.B. Wicker, and P. Frigola: Acta Mater., 2011, vol. 59, pp. 4088-99.

23. A. Strondl, R. Fischer, G. Franmeyer, and A. Schneider: Mater. Sci. Eng. A, 2008, vol. 480, pp. 138-47.

24. R.T. Quinn, R.W. Kraft, and R.W. Hertzberg: Trans. ASM, 1969 , vol. 62 , pp. $38-44$.

25. D. Senicourt and P. Annarumma: C.R. Acad. Sci., 1969, Ser. C, vol. 269, pp. 591-99.

26. P. Annarumma and M. Turpin: Metall. Trans., 1972, vol. 3, pp. $137-43$.

27. L.E. Murr: Interfacial Phenomena in Metals and Alloys, AddisonWesley Publishing Co., Reading, MA, 1975, reprinted 1990 and available from CBLS.CBLS.com.

28. L.E. Murr, E.V. Esquivel, S.A. Quinones, S.M. Gaytan, M.I. Lopez, E.Y. Martinez, F. Medina, D.H. Hernandez, E. Martinez, J.L. Martinez, S.W. Stafford, D.K. Brown, T. Hoppe, W. Meyers, U. Lindhe, and R.B. Wicker: Mater. Charact., 2009, vol. 60, pp. 96-105.

29. C. Radhakrishna, K.P. Rao, and S. Srinivas: J. Mater. Sci. Lett., 1995, vol. 14, pp. 1810-12.

30. B.H. Kear, J.M. Oblak, and A.F. Giamei: Metall. Trans., 1970, vol. 1, pp. 2477-86. 